\title{
The effect of Authentic Leadership and organizational bullying on job alienation with the mediating role of organizational culture
}

Fatemeh Hazratian $^{1 *}$, Behnaz Mohajeran ${ }^{1}$, Hasan Ghalavandi ${ }^{1}$

1. Educational Management, Urmia University, Urmia, Iran

Received: 19 September 2021

Accepted for publication: 5 December 2021

[EPub a head of print-13 December 2021]

Payesh: 2021; 20 (6): 671- 686

\begin{abstract}
Objective(s): The main purpose of this study was to investigate the effect of authentic leadership and organizational bullying on job alienation with the mediating role of organizational culture among faculty members of Tabriz University of Medical Sciences.

Methods: This was a descriptive study using the structural equation modeling. A random sample of faculty members of Tabriz University of Medical Sciences participated in the study. To collect the data four standard questionnaires were used to assess the variables of authentic leadership, organizational bullying, organizational culture, and job alienation. The structural equation modeling (partial least square-pls) was used to determine the effect of authentic leadership, organizational bullying on job alienation, with the mediating role of organizational culture.

Results: The results showed that reliable leadership has no direct effect on job alienation of faculty members of Tabriz University of Medical Sciences, but the results were significant with the mediating role of organizational culture. Also, organizational bullying did not show significant direct effect on job alienation. The indirect effect of organizational bullying on job alienation became significant with the mediating role of organizational culture.

Conclusions: Authentic leadership and organizational bullying due to organizational culture has an effect on job alienation among university faculty members.
\end{abstract}

Key words: Authentic Leadership, organizational bullying, job alienation

\footnotetext{
* Corresponding author: Educational Management, Urmia University, Urmia, Iran
}

E-mail: hazratianf@yahoo.com 


\title{
بررسى تاثير رهبرى موثق و قلدرى سازمانى بر ازخودبيكانكى شغلى با نقش ميانجى فرهنك سازمانى
}

\author{
فاطمه حضر تيان '، بهناز مهاجران'، حسن قلاوندى' \\ 1. انشكده ادبيات و علوم انسانى، دانشخاه اروميه، اروميه، ايران
}

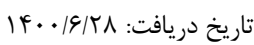

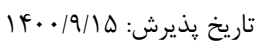

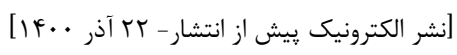

|f نشريه

جكيده

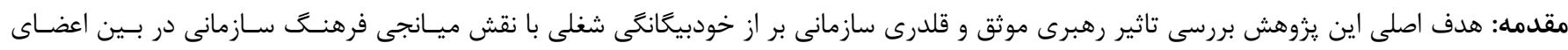

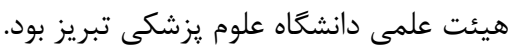

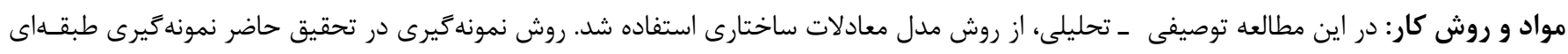

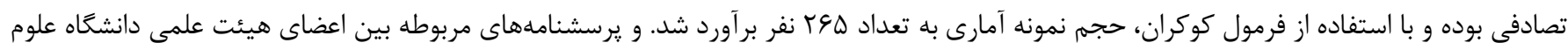

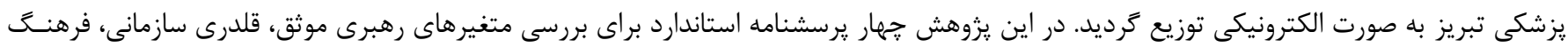

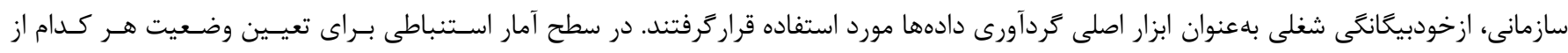

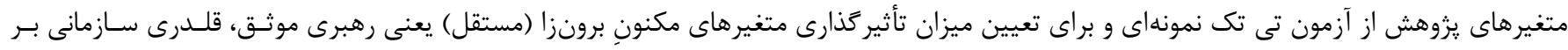

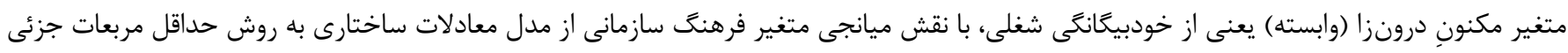
(pls)

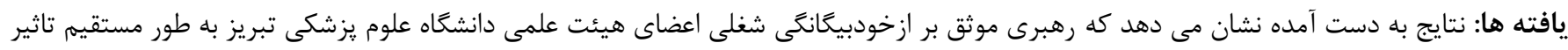

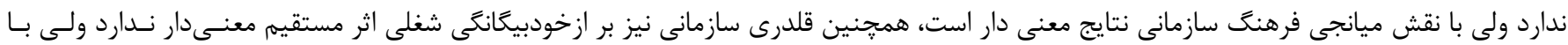

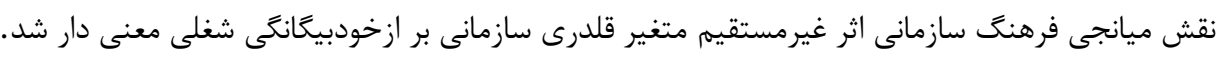

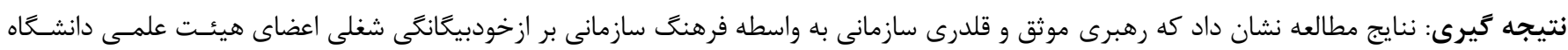
علوم يزشكى تبريز تاثير دارد. كليد وازه ها: ازخودبيخانكى شغلى، رهبرى موثق، قلدرى سازمانى، هيئت علمى، دانشكاه علوم يزشكى تبريز 
يكى ديكر از مههمرين عواملى كه سلامت روانى و جسـمى كاركنـان را به طور جدى در سازمانها به خطر مسى انسدازد، قلـدرى سـازمانى

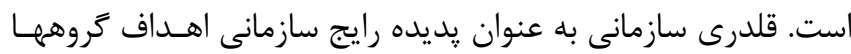

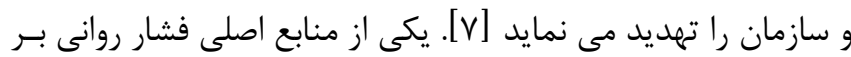

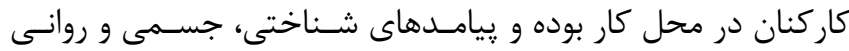

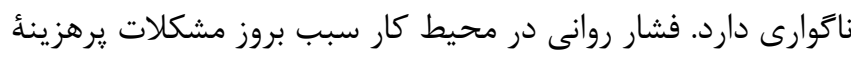

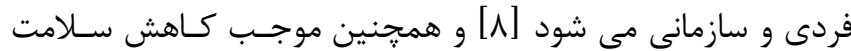

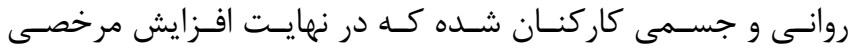

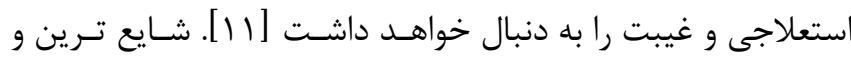
قابل تحمل ترين نوع قلدرى در سازمانها، قلدرى مرتبط با كار اسـت

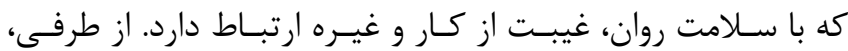

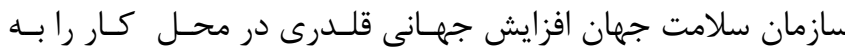

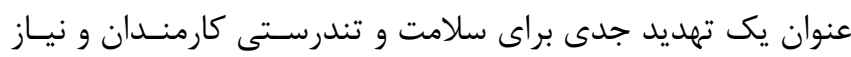

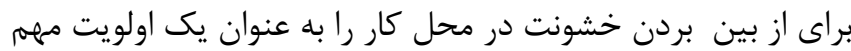

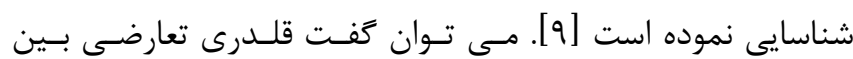
شخصى است كه در سطح فـردى بــه شخصـيت قربانيـان و قلـدران

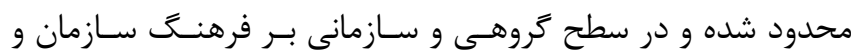

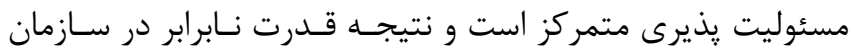

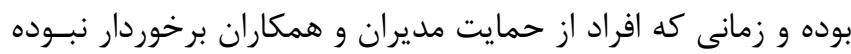

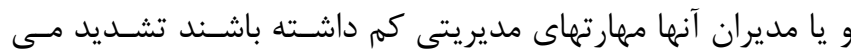

شود [• [1] نتايج تحقيقات نشان مى دهد كـه اسـتفاده از شـيوه هــاى رهبـرى

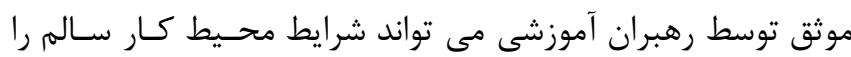

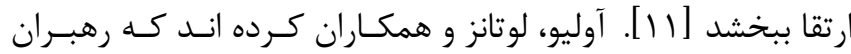

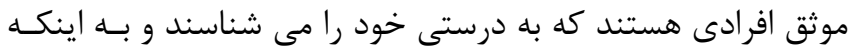

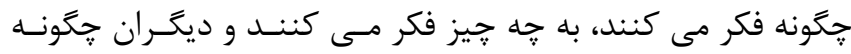
آنها را مى بينند و نسبت به ارزشها و ديـدكاه هـاى اخلاقىى، نقــاط

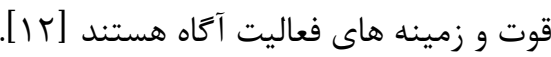

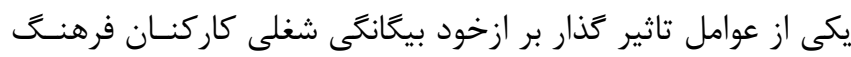

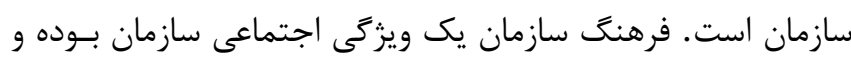

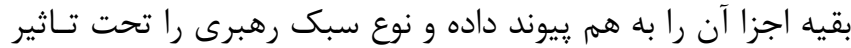

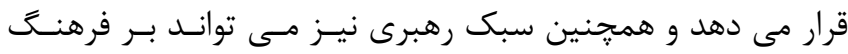

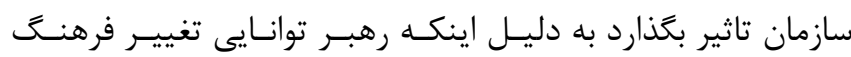

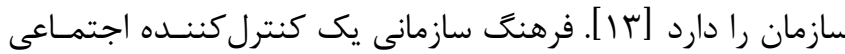

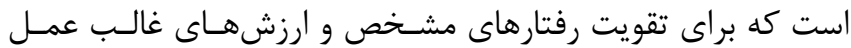

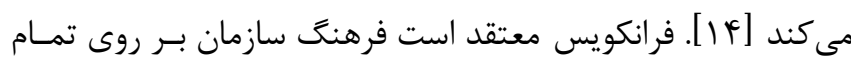

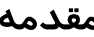

سازمانها همواره موضوع مورد علاقه براى مطالعه هسـتند. همجنــين سازمان ها براى ييخيرى هدفهاى دستهجمعى، سازوكارهاى حياتى

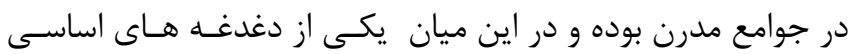

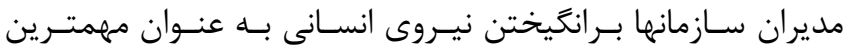

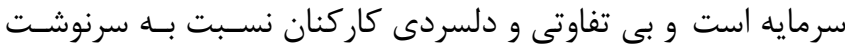

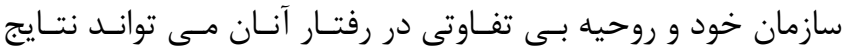

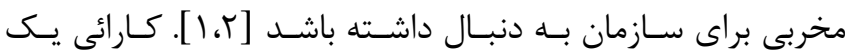
دانشكاه به اثربخشى و كيفيت كاركنان آن بخصوص اعضـاى هيئــت

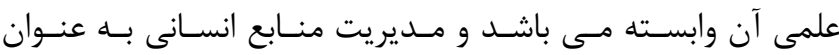

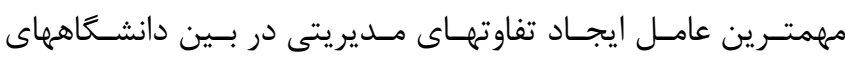

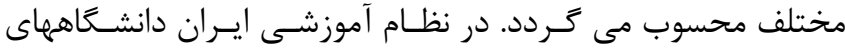

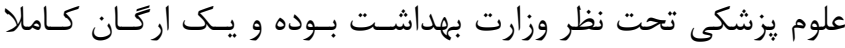
دولتى مى باشد و اعضاى هيئت علمى در اين سازمان، كارمند دولت

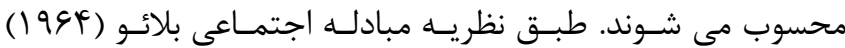

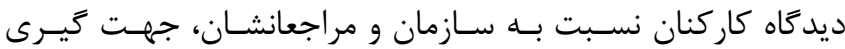

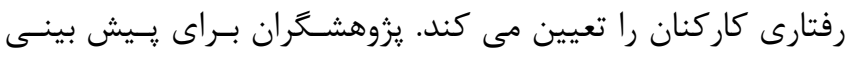

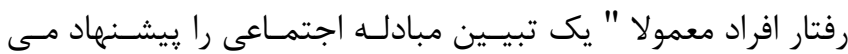

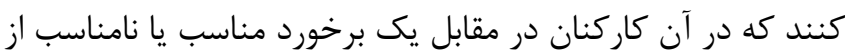

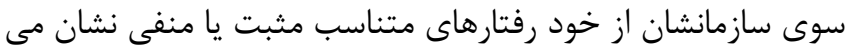

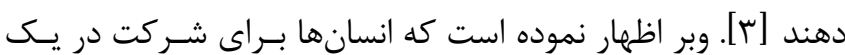

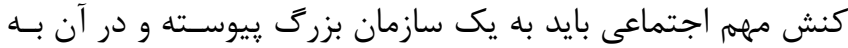
انجام وظايف خاص يرداخته و براى يذيرفته شدن در آن بايد آرزوها

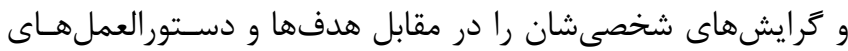
غيرشخصى حاكم بر سازمان، قربانى نمايند [F]

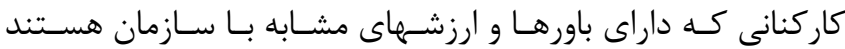

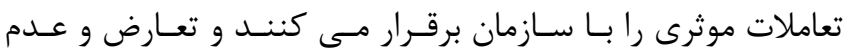

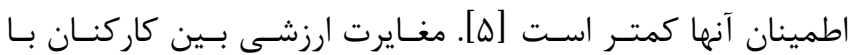

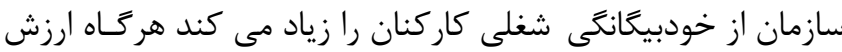

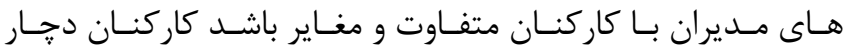

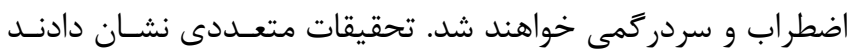

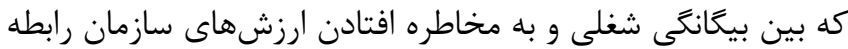

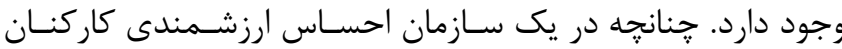

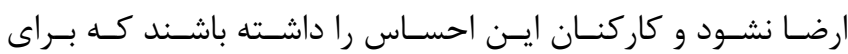

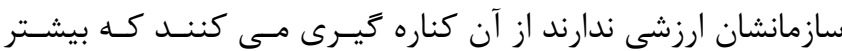

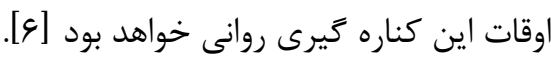


تاثير رهبرى موثق و قلدرى سازمانى بر از خودبيخانكى شـغلى بـاــا نقش ميانجى فرهنگ سازمانى در بين اعضاى هيئت علمى دانشـاه

علوم يزشكى تبريز بود.

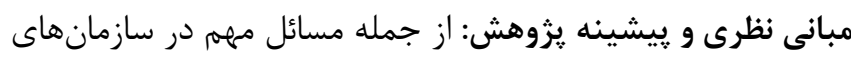

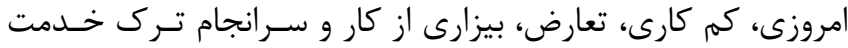

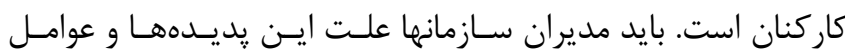

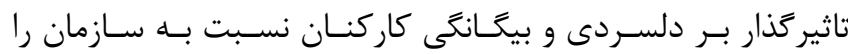

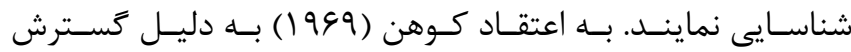

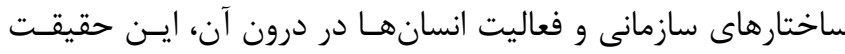

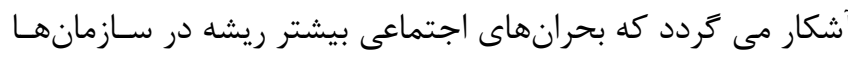
دارند. يكى از اين بحران ها كه توسط انديشمندان مورد مطالعه قـرار

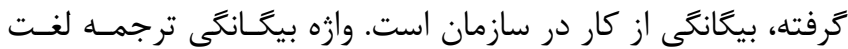

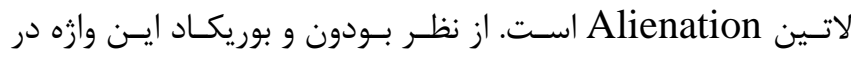

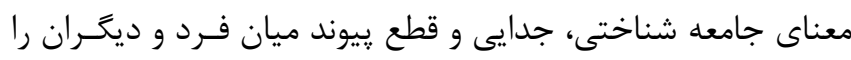

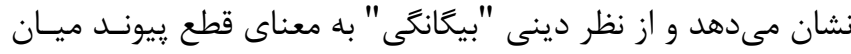

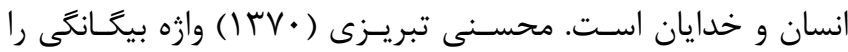

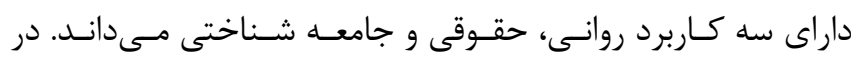
معناى جامعه شناختى، بيكانكى به تنفر يا بيزارى در احساس و نيـز

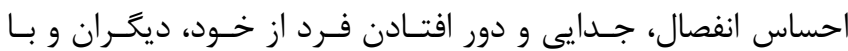

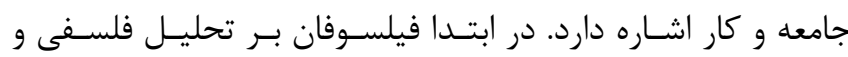

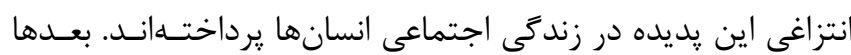

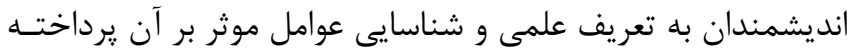

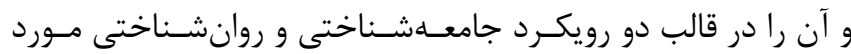

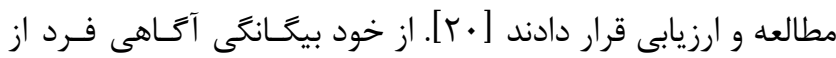

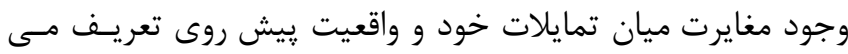

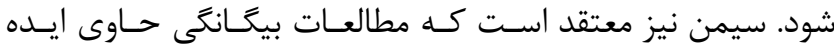

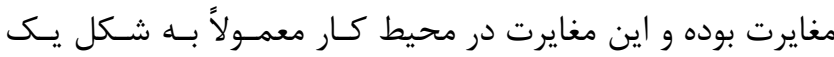

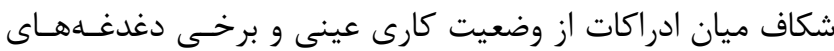

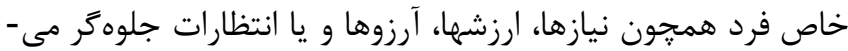

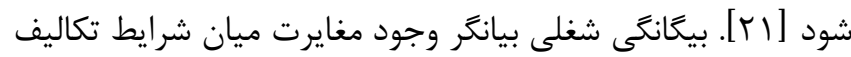

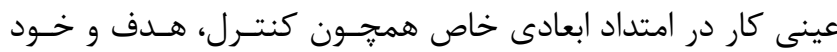

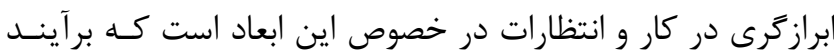

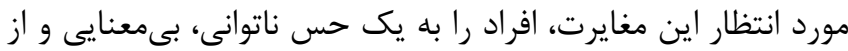

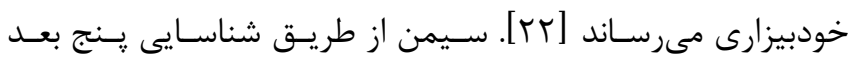
ازخودبيعانكى شغلى اين مفهوم را شفاف تر نمود، رِـنج بعـد مطـرح
تعاملات سازمان اثركذار است [ه 1]. از نظر تورمينــا يكـى از عوامـل

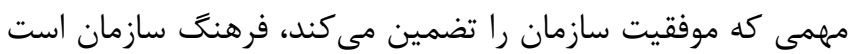

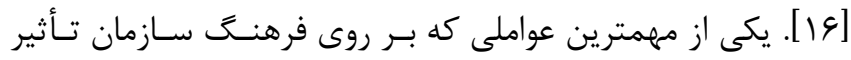

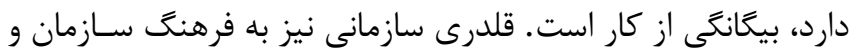

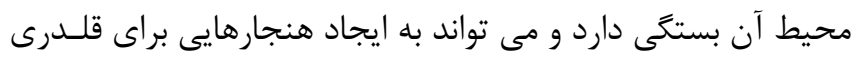

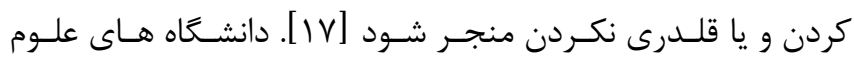
يزشكى و مراكز بهداشتى، درمانى به دليل اهميـت وظـايفى كـهـ در

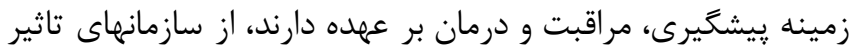

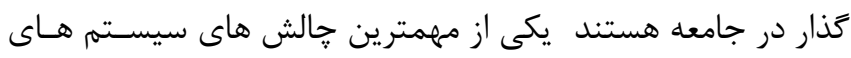

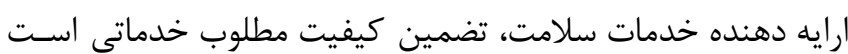

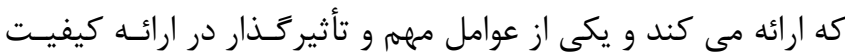
نامطلوب خدمات بهداشتى درمانى، عوامل انسانى است كه مي تواند

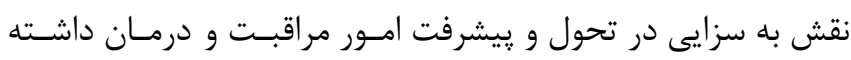

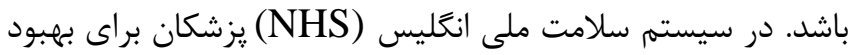
نتايج مراقبت هاى بهداشتى نقش رهبرى سيستم را در كنار مديران

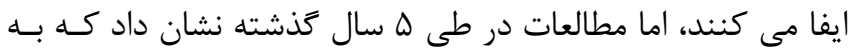

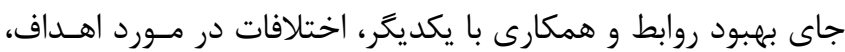

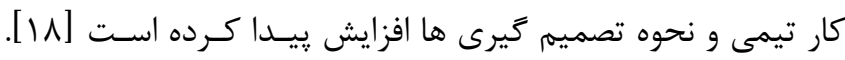

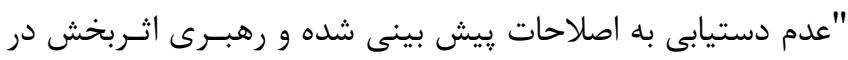

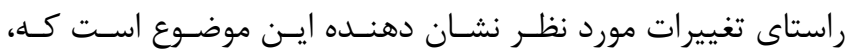

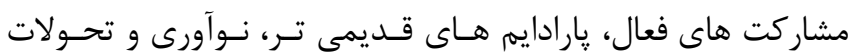

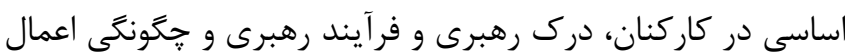

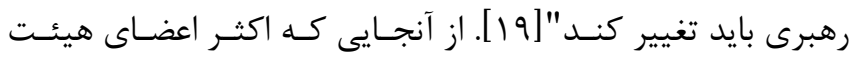

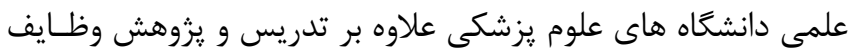

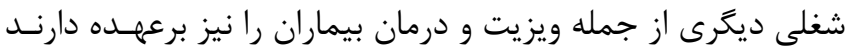

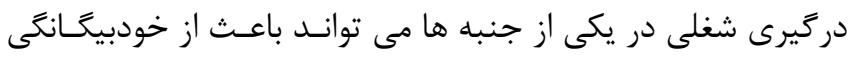

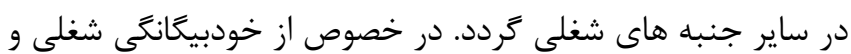

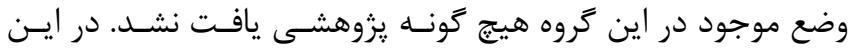

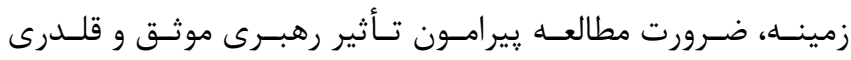

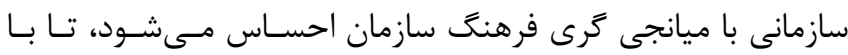

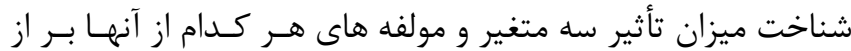

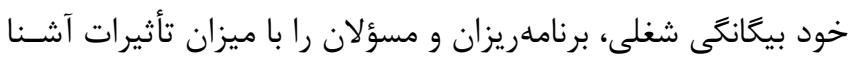

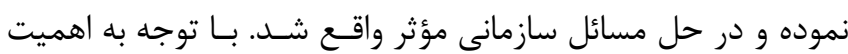
موضوع و حساسيت و تأثير عملكرد اعضـاى هيئست علمسى دانشــاه هاى علوم يزشكى در فرآيند بسيار مهمم آموزش، يزوهش و همجنين

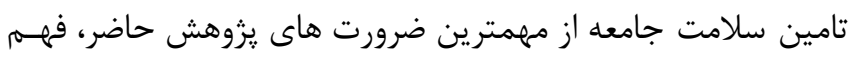


براى قلدران وجود دارد [rه]]. جالمه، بيان نموده اسـت كـه قلـدرى

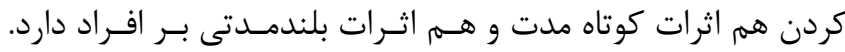

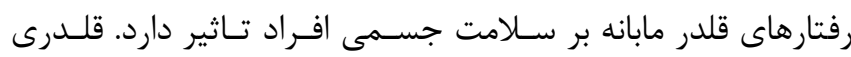

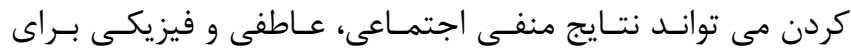

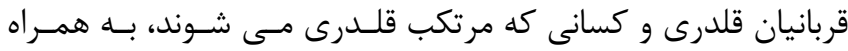

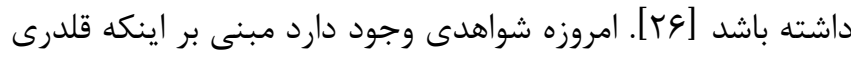

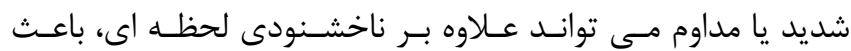

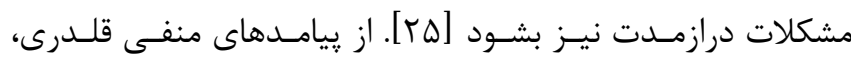

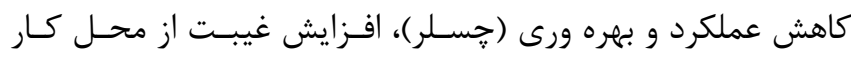

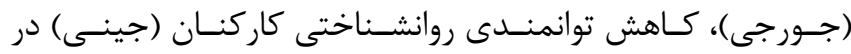

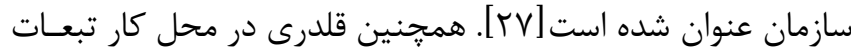
زيادى براى شخص قربانى قلدرى، شخص قلدر و شاهدان قلـدرى و واندان

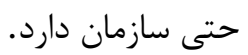

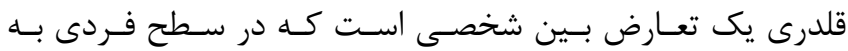
شخصيت قربانيان و قلدران محدود مى شد و در سـطح گروهـى يـا

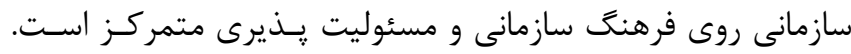
تحقيقات نشان مى دهد قلدرى نتيجه قدرت نـابرابر اسـت و شـامل فئل

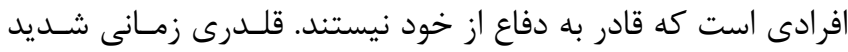

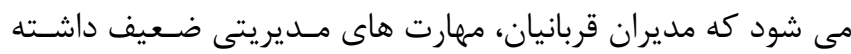

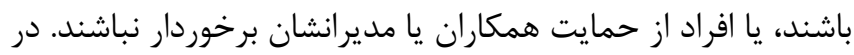

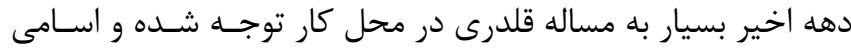

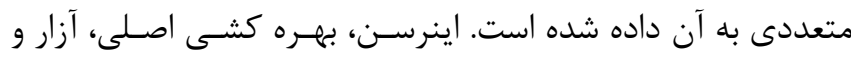

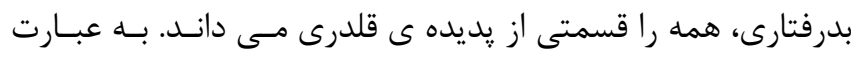

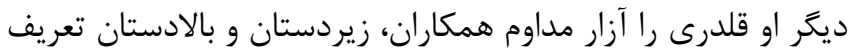

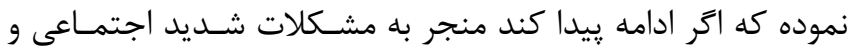

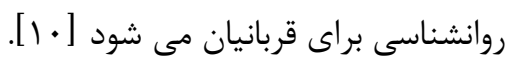
رفتار قلدرى در محل كار به وسيله ى هول و كوير اندان اندازه كيرى شده كه شامل جهار دسته است:

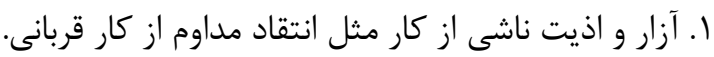

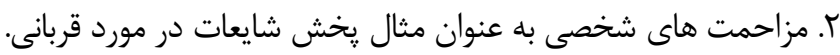

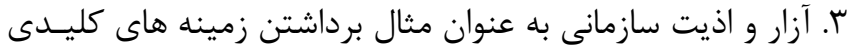

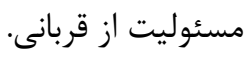

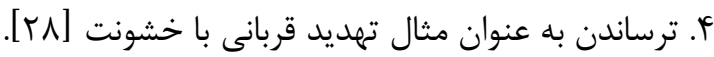

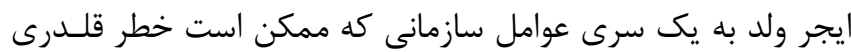

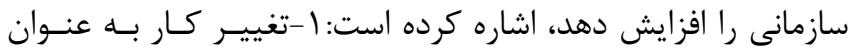

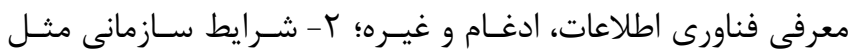

() ناتوانى، يعنسى فقـدان اسـتقلال و خودمختـارى در فعاليتهـاى كارى در كاركنان. T) بـى معنــايى، يعنسى نـاتوانى در ارتبـاط دادن تلاشهاى فردى به يك هدف بالاتر. ب) بى هنجارى، انجام رفتارهاى تاييدنشده براى رسيدن به هدفهاى معسين. \&) انزواطلبسى، زمـانى اتفاق مى افتد كه هنجارى هاى فردى در رسـيدن بــه اهـداف مــوثر

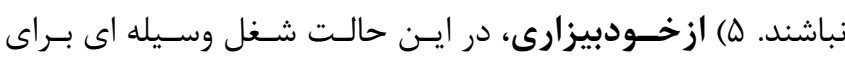

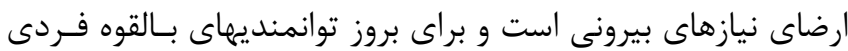

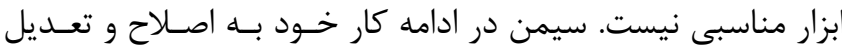

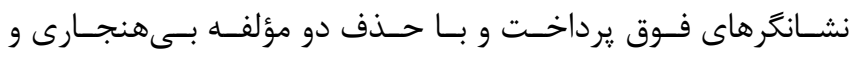
انزواطلبى (كنارهخيرى)، كار خود را با سه مؤلفه بـاقى مانـده دنبـال

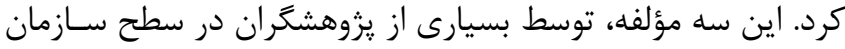

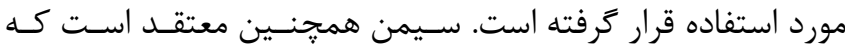

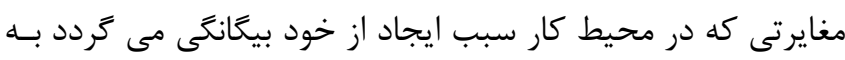

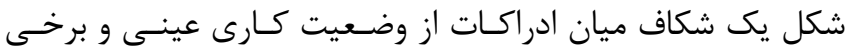
دغدغه هاى خاص فرد مانند ارزش ها و يا انتظارات نمايان مى شـود آديات

[C.Tr]

اشخاصى كه ازخودبيكانكى شغلى را تجربه مى كنند با افراد خانواده،

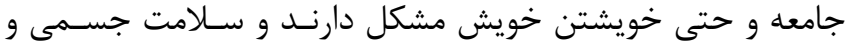

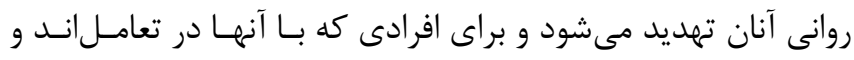

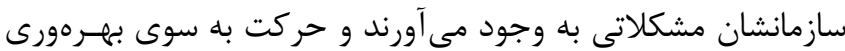
سازمان را با كندى و كاه توقف روبارو مى كنند [Yr]

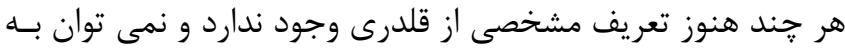

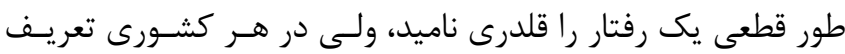

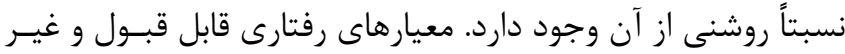

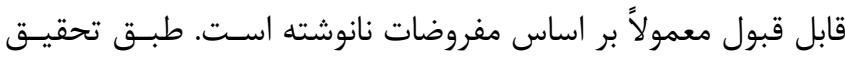

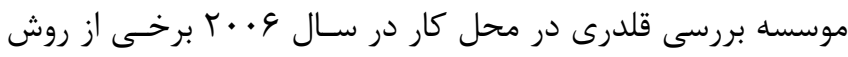

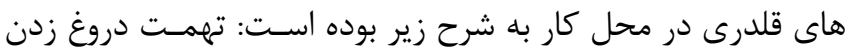

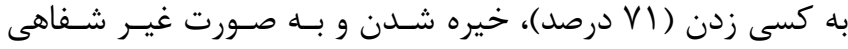

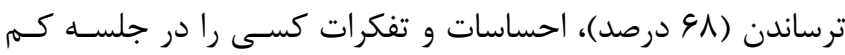

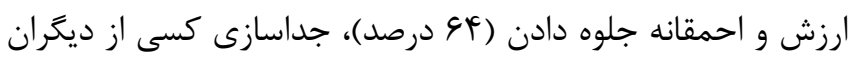

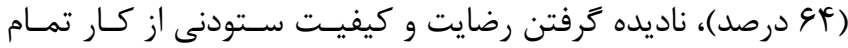

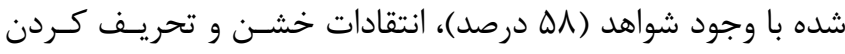

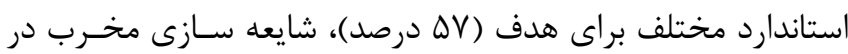

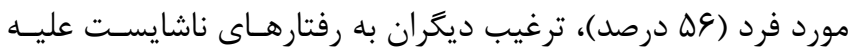

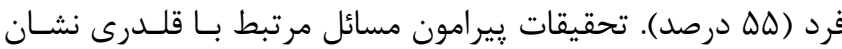

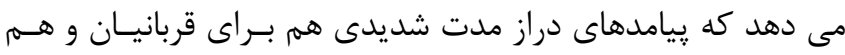


بــراى آزمـــون روابــط متغيرهــا از معــادلات ســاختارى اســتفاده كرديد(شكل شماره(). مواد و روش كار يزوهش حاضر از نظر هدف كاربردى بوده و به دنبال توسعه دانسش

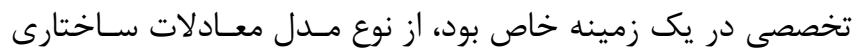

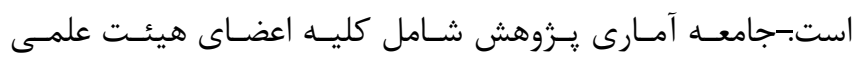

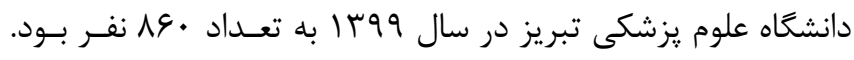

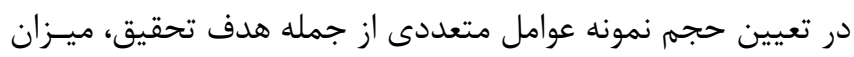

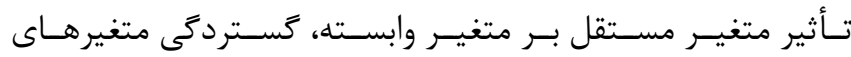

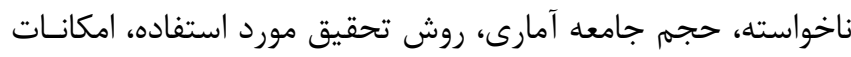

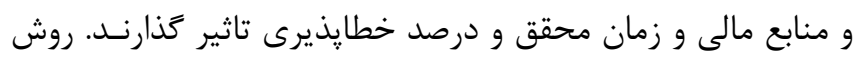

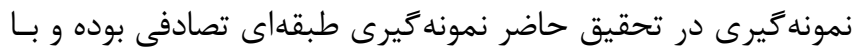

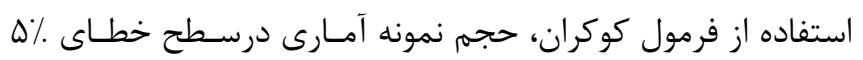

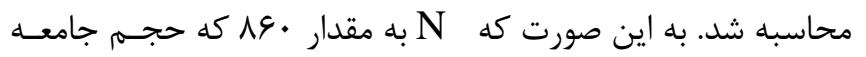

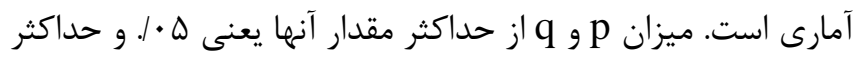

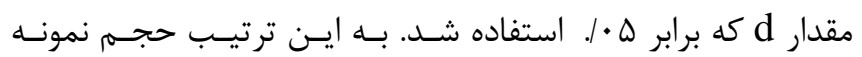

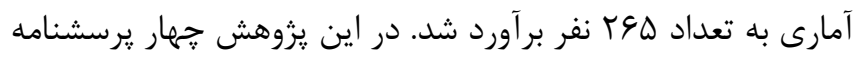

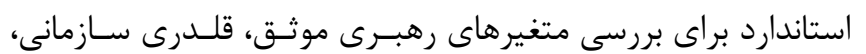

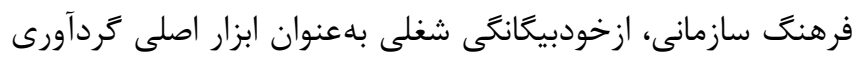

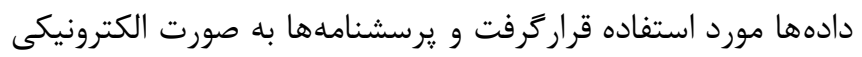
توزيع كرديد.

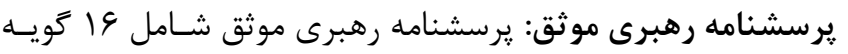

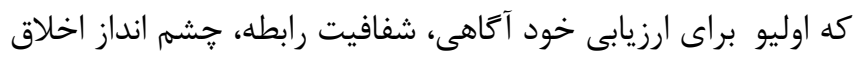

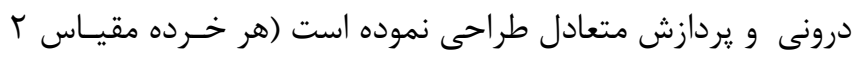

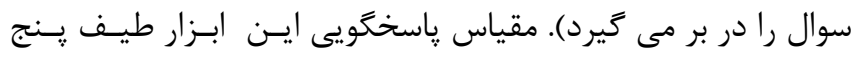

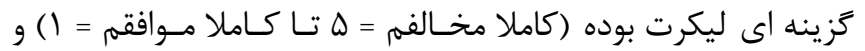

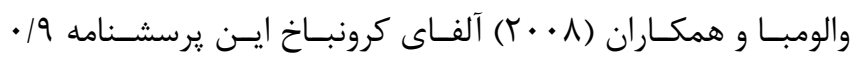

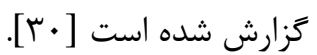

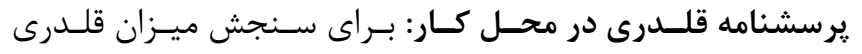

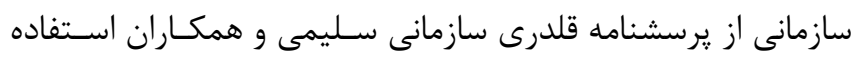

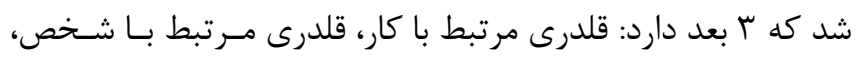

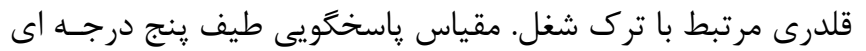

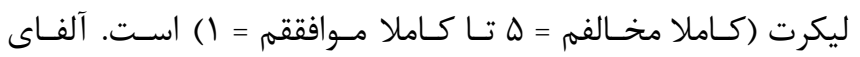

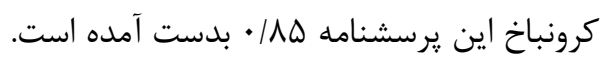

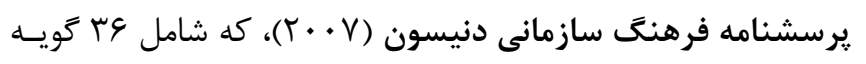

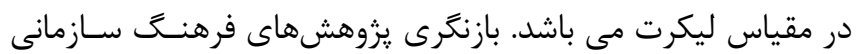

فشار كارى و تقاضاهاى عملكردى بالا از نيروى كار، عدم اطمينـان و

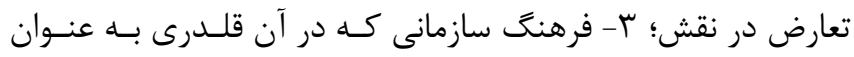

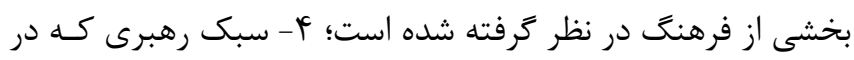

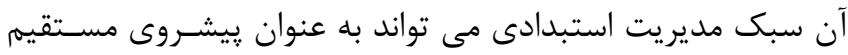

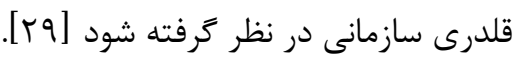

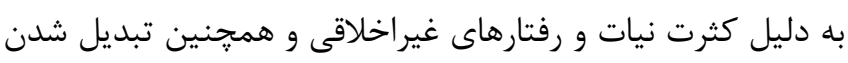

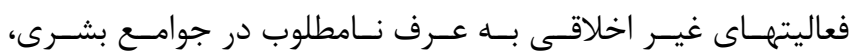

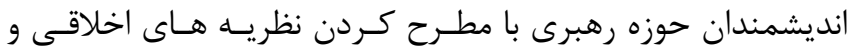

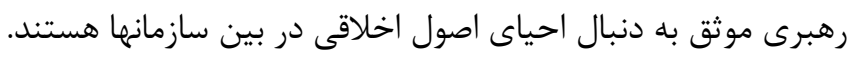

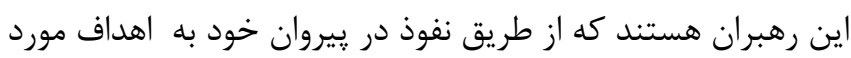

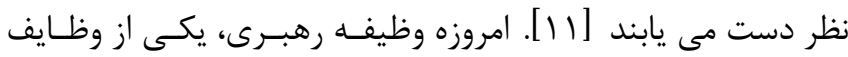

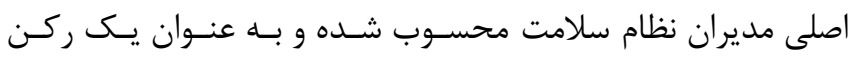

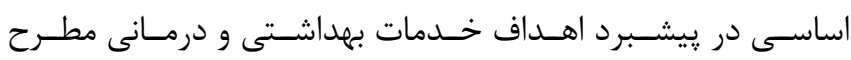

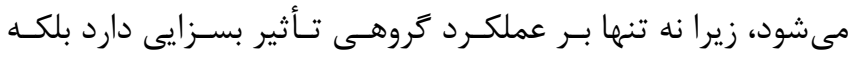

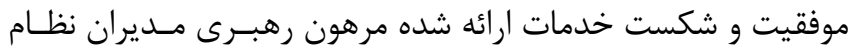

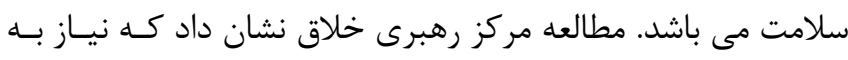

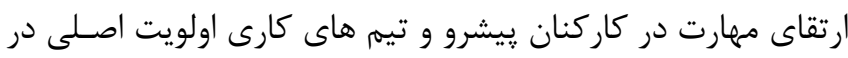

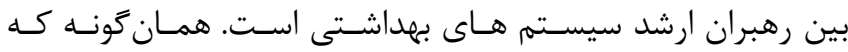

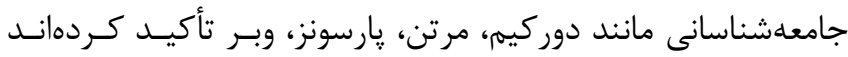

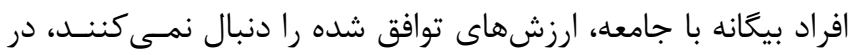

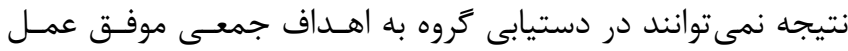

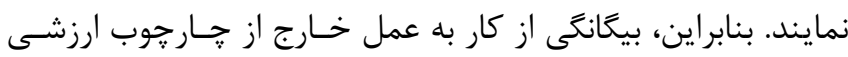

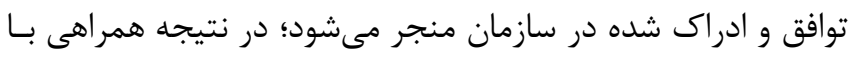

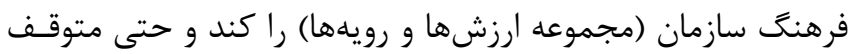

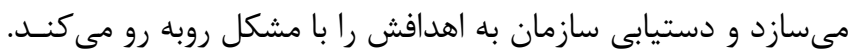

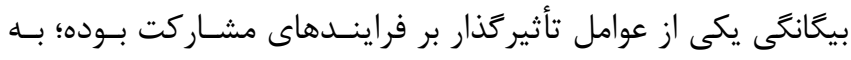

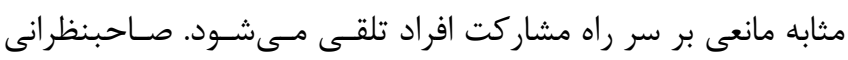

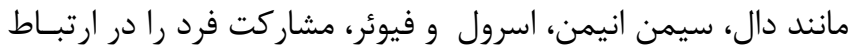

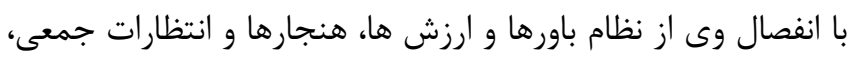

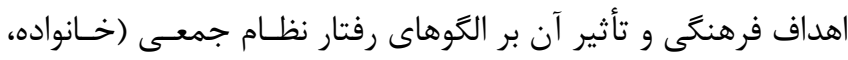
سازمان و ساير نظامات اجتماعى) توضيح داده اند.

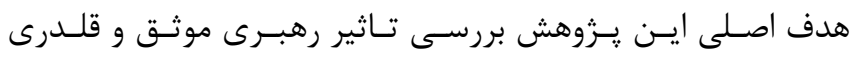

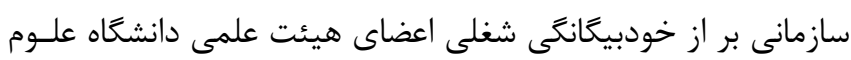

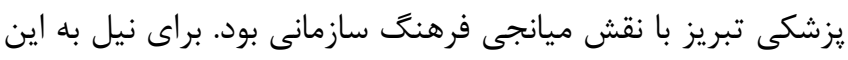
هدف اصلى يزوهش و به منظور يِيشبينى احتمالى وجود رابطه بين بين

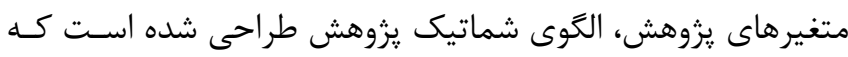


كردهاند و مقدار AVE بالاى ها • روايى همكراى قابلقبول را نشـان

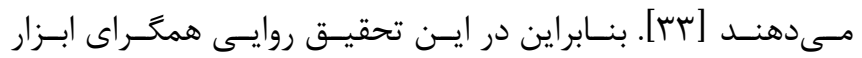

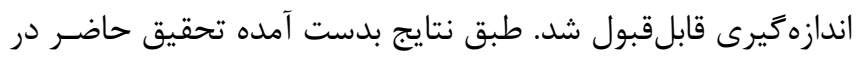
جدول شماره f مي توان كفت همه مولفه هاى ابزار سنجش روايسى

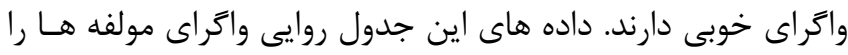

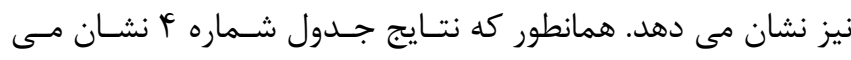

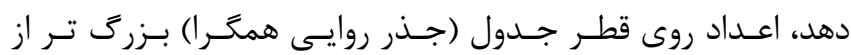
همبستگى هر مولفه با مولفه هاى ديكر است كه نشان مى دهد كـهـ تمامى مولفه هاى ابزار از روايى واكرا برخوردار است.

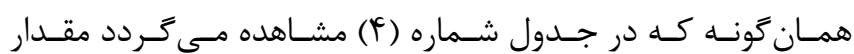

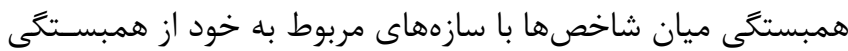

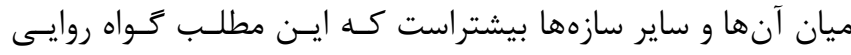

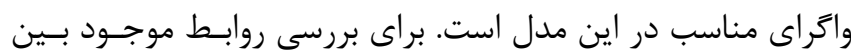

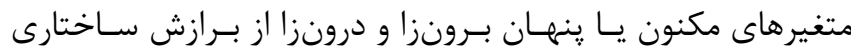

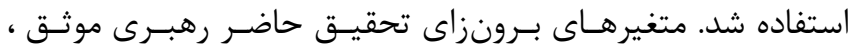

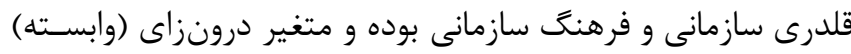
آن از خودبيكانكى شغلى است. براى اين كار از R2 و و معيار اسـتون

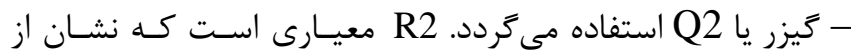

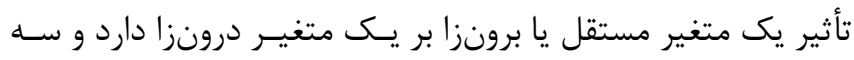

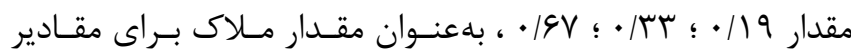

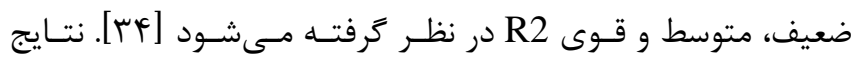

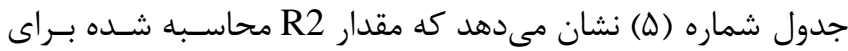
مدل تحقيق مناسب بودن برازش مدل ساختارى رانشان مى ده دهد.

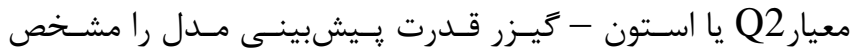

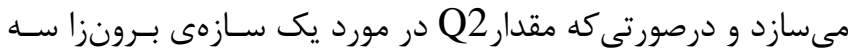

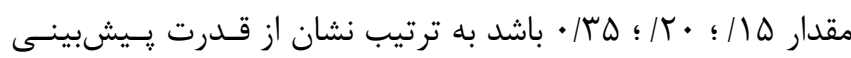

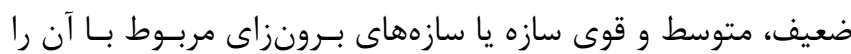

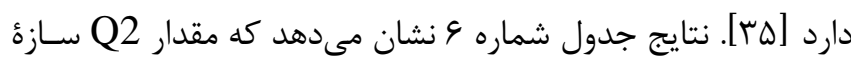

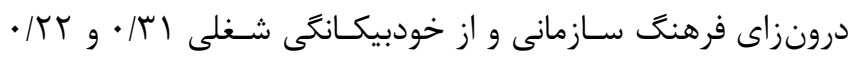

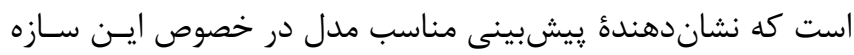

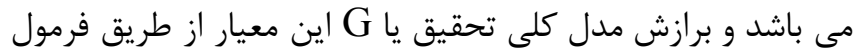
زير محاسبه مى

\section{$\sqrt{\text { communalities } \times R-\text { squares }}=\mathrm{GOF}$}

ommunalitiesc

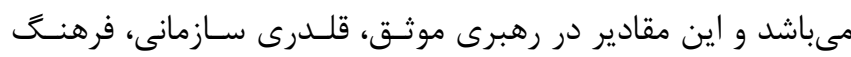

نشان مى دهد كـه مــدل دنيسـون از فرهنــ سـازمانى، بسـيارى از

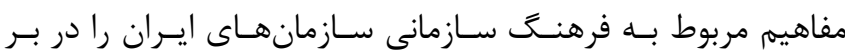

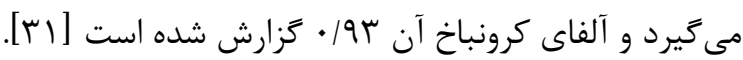

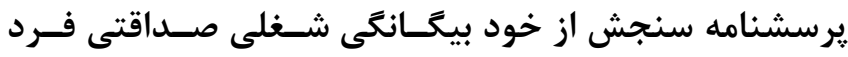
(I TAN)

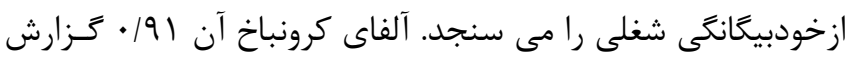

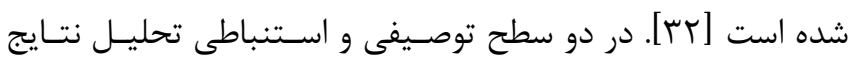

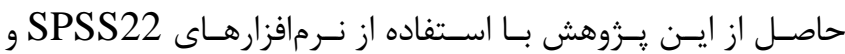

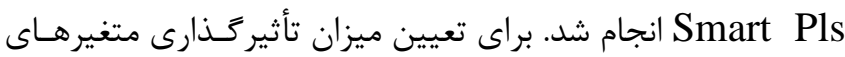

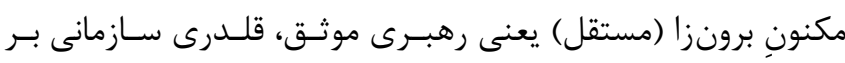

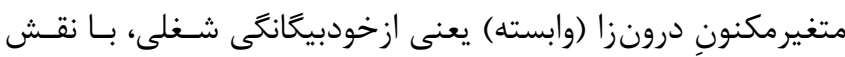

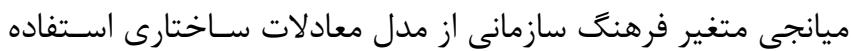

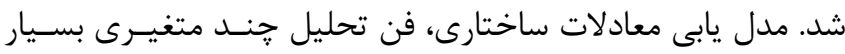

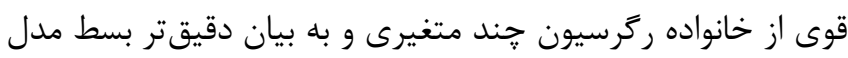

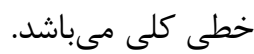

يافته ها

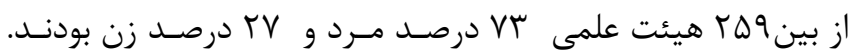

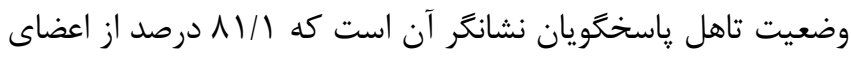

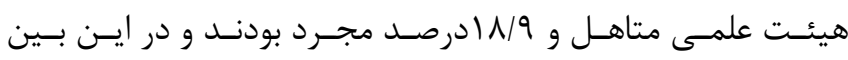

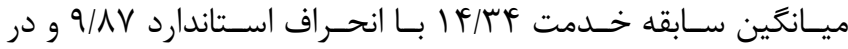

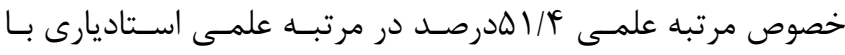

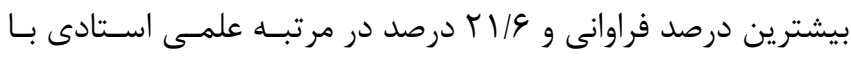

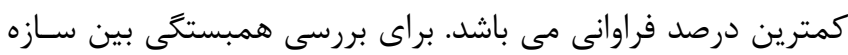

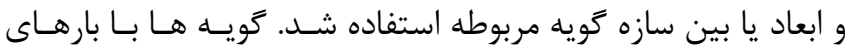

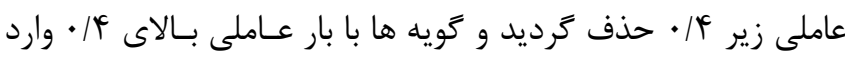

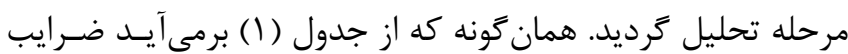

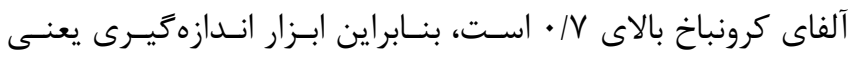

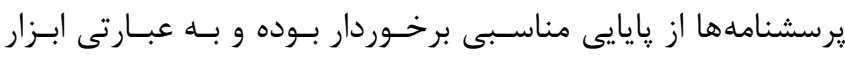

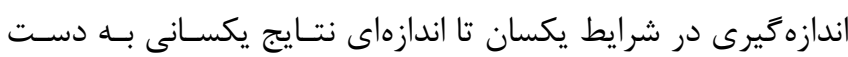

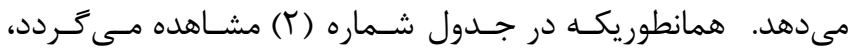

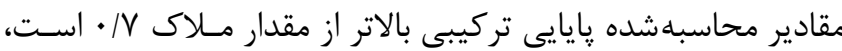

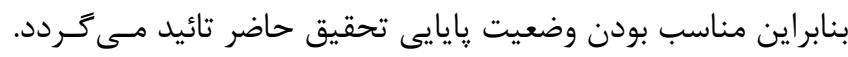

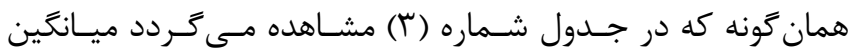

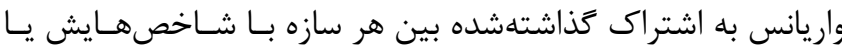

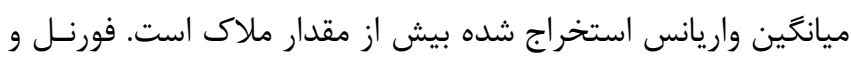

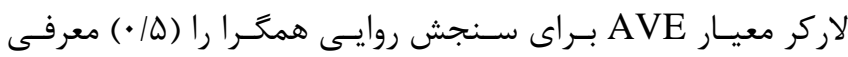


مقدار وج. براى VAF بدين معنى است كه بيش از وץ درصد از

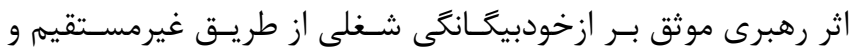
متغير ميانجى فرهنَ سازمانى تبيين مى شود. آنى

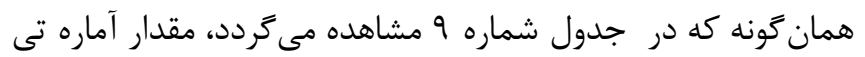

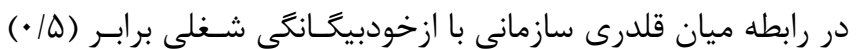

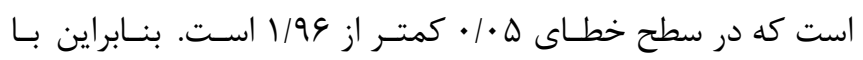

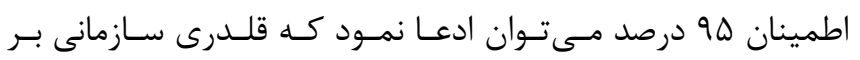
ازخودبيخانكى اثر مستقيم معنى دار ندارد. نتايج بررسى تأثير متغيــر

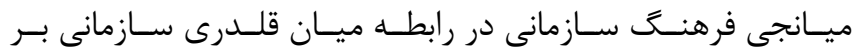

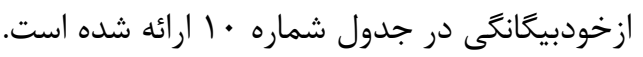

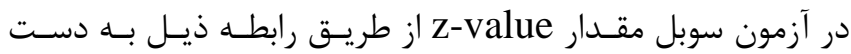

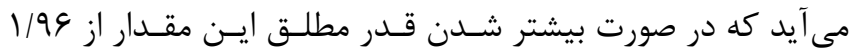

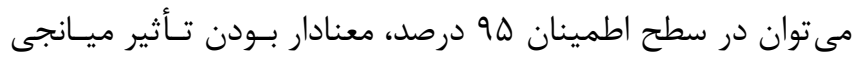

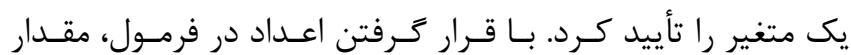

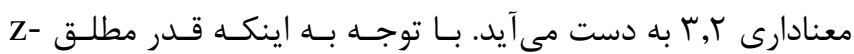

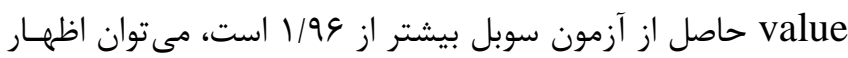

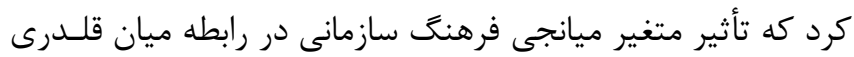

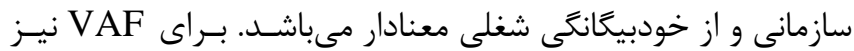

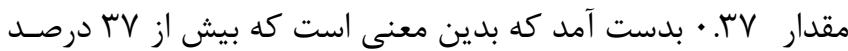

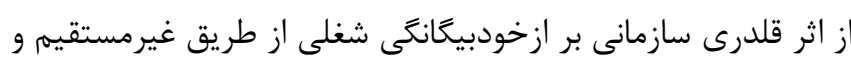

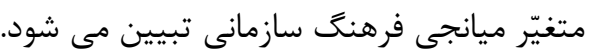

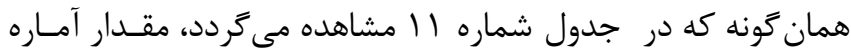

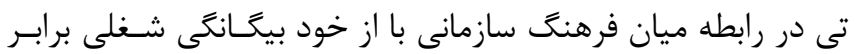

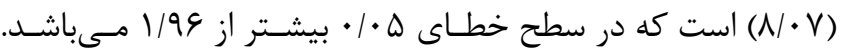

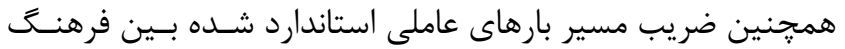

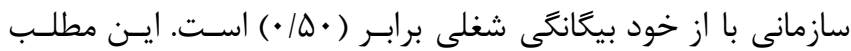

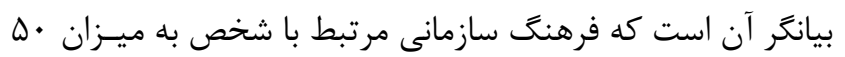

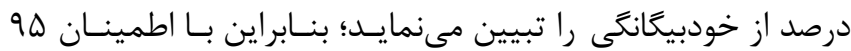

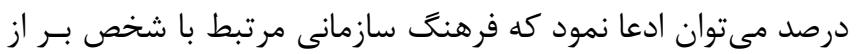
خودبيعانگى اثر مستقيم معنى دارى دارد.

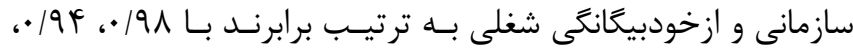

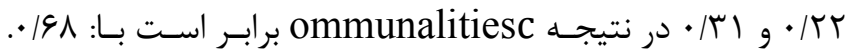
حصول \&1|• براى GOF در مورد تحقيق حاضر مىتوان به مناسب

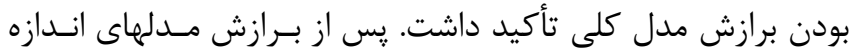

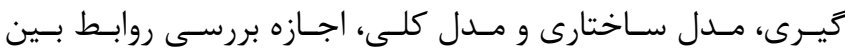

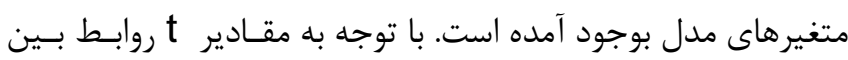

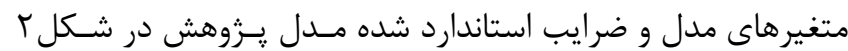
مشخص شده است.

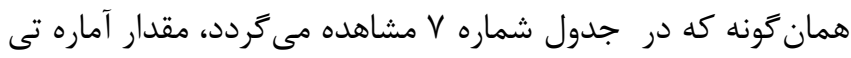

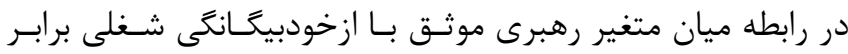

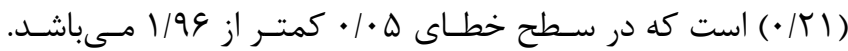

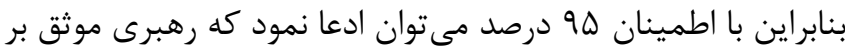

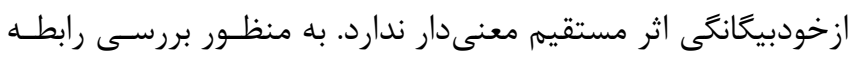

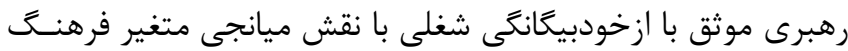

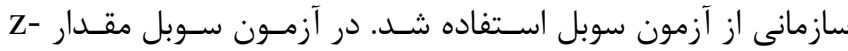

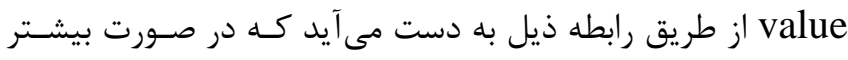

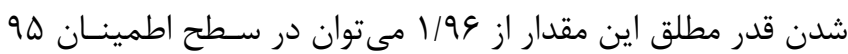
درصد، معنادار بودن تأثير ميانجى يك متغير ران رأتيد أنيد كرد. Z-value $=\frac{a \times b}{\sqrt{\left(b^{\Upsilon} \times s_{a}^{\Upsilon}\right)+\left(a^{\Upsilon} \times s b^{\Upsilon}\right)+\left(s_{a}^{\Upsilon} \times s_{b}{ }^{\Upsilon}\right)}}$

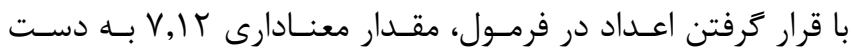

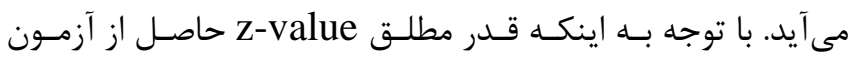

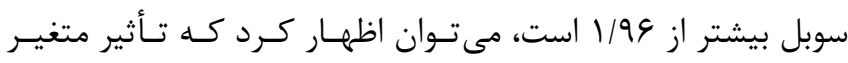

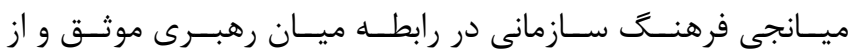

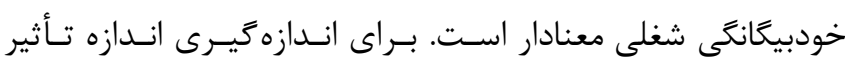

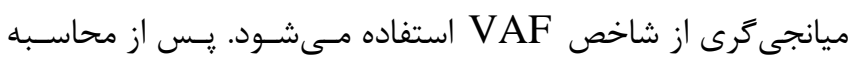

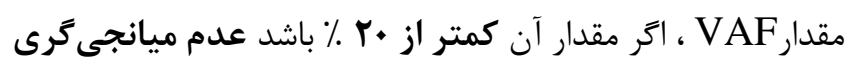
برقرار است. (Absecnce mediation) $\mathrm{VAF}=(\mathrm{a} \times \mathrm{b}) /(\mathrm{a} \times \mathrm{b})+\mathrm{c}=\cdot . \mathrm{rq}$ 
سال بيستم، شماره ششم، آذر ـدى .. $\int_{4}^{\infty}$

جدول ا: ضرايب هايايى آلفاى كرونباخ يرسشنامهها

\begin{tabular}{|c|c|c|c|}
\hline ضريب آلفاى كرونباخ & متغيرها & ضريب آلفاى كرونباخ & \\
\hline$\cdot / / 991$ & قلدرى سازمانى & $\Lambda \Delta 1 / \cdot$ & رهبرى موثق \\
\hline •/ १९९ & قلدرى مرتبط با كار & $\Lambda \kappa r /$. & شفافيت رابطه \\
\hline$\cdot / V \Delta \Delta$ & قلدرى مرتبط با شخص & $\wedge \notin \uparrow /$. & جشم انداز اخلاق درونى \\
\hline$\cdot / V r V$ & قلدرى مرتبط با نيت ترك شغل & $\Lambda \Delta F /$. & يردازش متعادل اطلاعات \\
\hline \multirow[t]{2}{*}{. /9TF } & فرهنَ سازمانى & 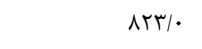 & خودآكاهى \\
\hline & & $.19 \cdot 1$ & ازخودبيگانكًى شغلى \\
\hline
\end{tabular}

\begin{tabular}{|c|c|c|}
\hline & \multicolumn{2}{|c|}{ جدول r: ضرايب هايايى تركيبى يرسشنامهها } \\
\hline هايايى تركيبى & 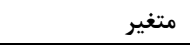 & 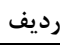 \\
\hline$\cdot / \wedge \Delta \Delta$ & رهبرى موثق & 1 \\
\hline$\cdot \mid \Lambda \cdot 1$ & 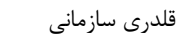 & r \\
\hline.$/ 94 F$ & فرهنَ سازمانى & r \\
\hline.$/ 911$ & ازخودبيكانكى شغلى & r \\
\hline
\end{tabular}

جدول זّ: روايى همكَراى يرسشنامههاى تحقيق

\begin{tabular}{|c|c|c|}
\hline مقدار ملاى & AVE & \\
\hline$\cdot / \Delta$ & . $19 \Delta \mathrm{H}$ & رهبرى موثق \\
\hline$\cdot / 0$ & $\cdot \mid \Delta s$ & قلدرى سازمانى \\
\hline$\cdot / \Delta$ & $\cdot / 0 \cdot 4$ & فرهنَ سازمانى \\
\hline$\cdot / \Delta$ & $\cdot|Q| \cdot$ & ازخودبيكانكى شغلى \\
\hline
\end{tabular}

\begin{tabular}{|c|c|c|c|c|c|c|c|c|c|c|c|}
\hline & شغلى ازخودبيحــــانكى & خودآكاهى & روثبــــى & رابطه شـافيت & سازمانى & قازمانى & 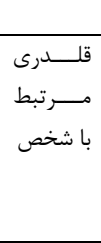 & 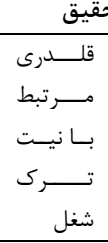 & 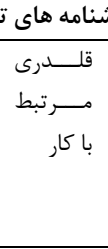 & 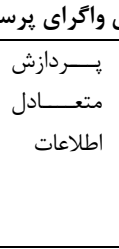 & 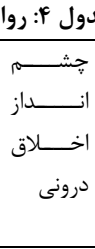 \\
\hline ازخودبيكانكى شغلى & $\cdot \mid \mathrm{VI}$ & & & & & & & & & & \\
\hline خودآكَاهى & $\cdot / \cdot v$ & $9+11$ & & & & & & & & & \\
\hline رهبرى موثق & $-\cdot / 1 r$ & $1 \cdot 11$ & $1 / \cdot \cdot$ & & & & & & & & \\
\hline شفافيت رابطه & $-\cdot / 11$ & $\cdot \mid 94$ & $\cdot / \wedge V$ & . AT & & & & & & & \\
\hline فرهنَ سازمانى & . AT & $-\cdot / \Delta \omega$ & -.191 & $-\cdot / \Delta V$ & $\cdot / V I$ & & & & & & \\
\hline قلدرى سازمانى & $\cdot / \Delta \Lambda$ & $-\cdot / 14$ & - & $-\cdot / r v$ & 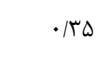 & $1 / \cdot \cdot$ & & & & & \\
\hline قلدرى مرتبط با شخص &.$/ 49$ & $-\cdot 1 \cdot v$ & $-\cdot / r 9$ & $-\cdot / r y$ & . & $\cdot / 19$ & $\cdot / V r$ & & & & \\
\hline قلدرى مرتبط با نيت ترك شغل & / $/ \Delta T$ &.$- \cdot 1 \cdot 1$ & $-\cdot / 10$ & $-\cdot / 19$ & $\cdot / r \Lambda$ & $\cdot / \wedge \gamma$ & $\cdot \mid 9 V$ & $\cdot / \wedge \Delta$ & & & \\
\hline قلدرى مرتبط با كار & $\cdot / \Delta \Lambda$ & $-\cdot / 1 \mathrm{r}$ &.$- / 44$ & $-\cdot / r \Lambda$ & $\cdot / 49$ & $\cdot / 94$ & $\cdot 19 V$ & $\cdot|\Lambda|$ & $\cdot / v V$ & & \\
\hline بردازش متعادل اطلاعات & $-\cdot / 1 \mathrm{~V}$ & $\cdot / \wedge$ &.$/ 94$ & .199 & $-\cdot / v r$ & $-\cdot / r$ & $-\cdot / r y$ & $-\cdot / 14$ & $-\cdot / r r$ & $\cdot / 19$ & \\
\hline جشم انداز اخلاق درونى & $-\cdot|r|$ & $\cdot|A|$ & .190 & $\cdot|\Lambda|$ &.$- / 94$ & $-\cdot / r \Lambda$ &.$- / 199$ & $-\cdot|r|$ & $-\cdot / r r$ & $\Delta \cdot / \Lambda$ & $\cdot / \wedge \Delta$ \\
\hline
\end{tabular}


سال بيستم، شماره ششم، آذر - دى ..

نشريه يزووهشده علوم بهداشتى جهاددانشحاهى

جدول ه: مقدار ضريب Rمدل

\begin{tabular}{|c|c|c|}
\hline R Square Adjusted & R Square & \\
\hline . $/ \Delta T H$ & . $/ D F T$ & ازخودبيكانكى شغلى \\
\hline . /9८V &.$/ 9 \Delta F$ & رهبرى موثق \\
\hline$\cdot / F V F$ & $\cdot / 4 \vee \wedge$ & فرهنَ سازمانى \\
\hline$\cdot / 909$ &.$/ 909$ & قلدرى سازمانى \\
\hline
\end{tabular}

جدول 9: ضريب Q2 - Q

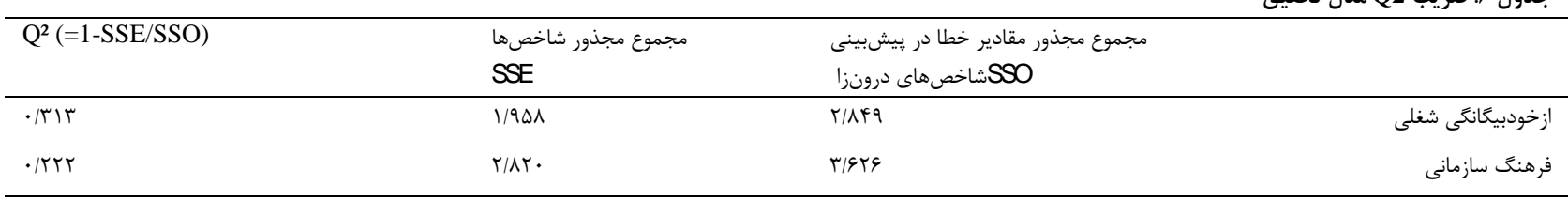

جدول V: نتايج آمارى روابط بين متغير رهبرى موثر و از خودبيكانكى شغلى

\begin{tabular}{|c|c|c|c|c|c|}
\hline سطح معنى دارى & 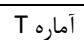 & انحراف معيار & ميانَين & مقدار ضريب & \\
\hline . &.$|r \||$ & $r / 99$. & $-\cdot / 1 T F$ & $-\cdot / V \vee \wedge$ & رهبرى موثق -> ازخودبيكانكى شغلى \\
\hline
\end{tabular}

جدول 1 : نتايج آمارى روابط بين متغير رهبرى موثر و از خودبيكانكى شغلى با نقش ميانجى فرهنگ سازمانى

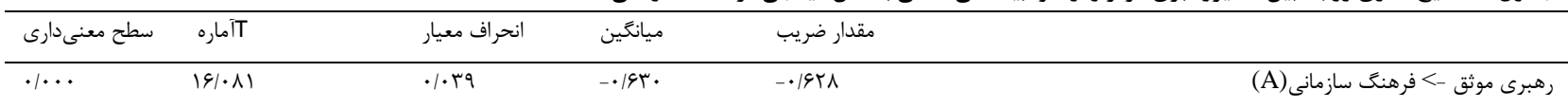

\begin{tabular}{|c|c|c|c|c|c|}
\hline 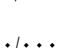 & (1, & ter & (s) & r. & (B) $1 \cdots=0$ \\
\hline & . & went & (2n & (2. & 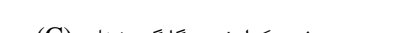 \\
\hline
\end{tabular}

رهبرى موثق -> ازخودبيكانكى شغلى (C)

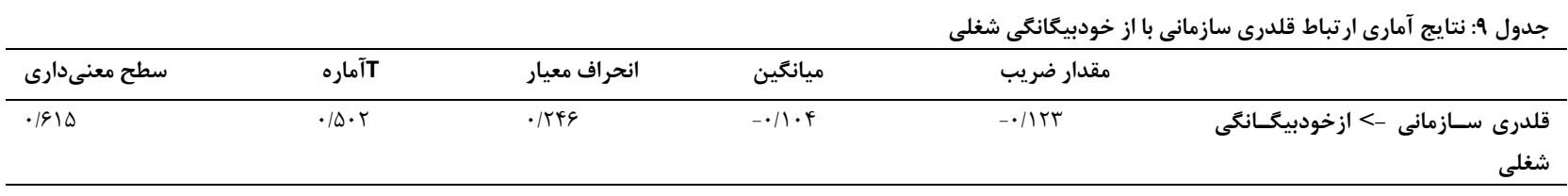

\begin{tabular}{|c|c|c|c|c|c|}
\hline سطح معنى دارى & آماره & انحر اف معيار & ازيانكَدبين & مقيان قلدرى س & جدول •ا: نتايج آمارى بررسى تأثير متغير \\
\hline$\cdot \%$ & $r / \Delta F \Delta$ & $.1 .4 T$ & $\cdot / / \Delta T$ & $\cdot / 1 \Delta$ & قلدرى سازمانى -> فرهنگ سازمانى ) Al \\
\hline$\cdot / \cdots$ & $N / F \mid \Delta$ & $\cdot / \cdot \Delta \wedge$ & .499 & $\cdot / 4 \wedge 9$ & فرهنكَ سازمانى -> ازخودبيكانكَى شغلى(B) \\
\hline$\cdot \mid 910$ &.$/ 49$ & D MFG & $-\cdot / 1 \cdot 4$ & . & قلدرى سازمانى -> ازخودبيكانكَى شغلى \\
\hline
\end{tabular}

جدول لا: نتايج آمارى بررسى ارتباط ميان فرهنَ سازمانى با از خود بيكانكى شغلى

\begin{tabular}{|c|c|c|c|c|c|}
\hline سطح معنى دارى & Tآماره & انحراف معيار & ميانكَين & مقدار ضريب & \\
\hline$\cdot \ldots$ & $\mathrm{N} / \cdot \mathrm{Vq}$ & .1 .94 & $\cdot / 0 \cdot V$ & $\cdot / 0 \cdot r$ & فرهنگَ سازمانى -> ازخودبيكانكَى شغلى \\
\hline
\end{tabular}




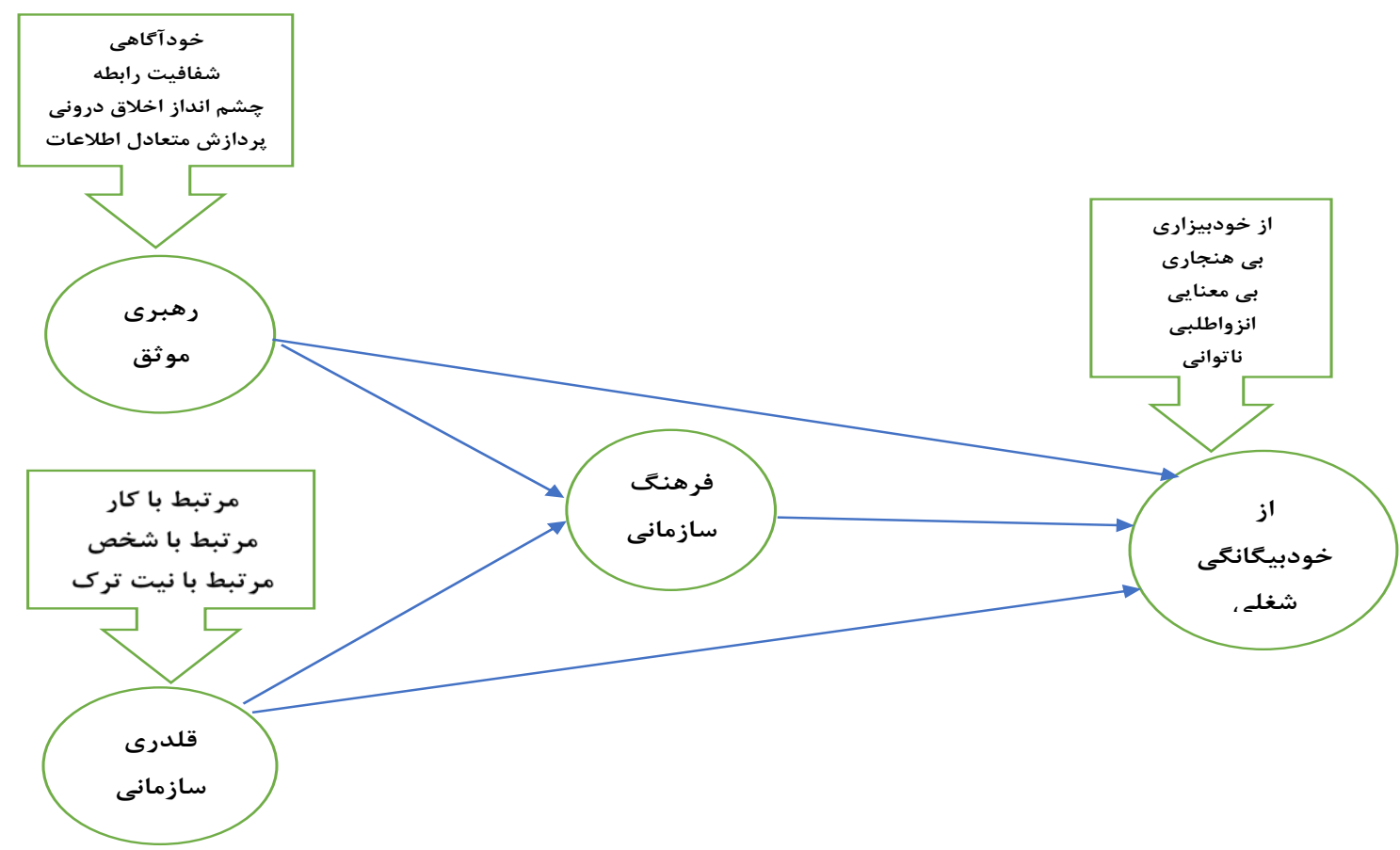

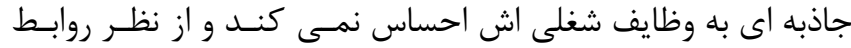

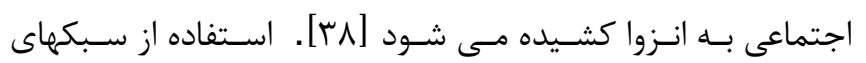

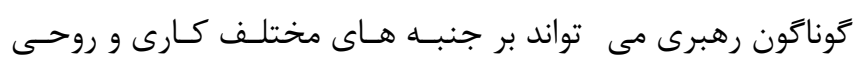
كاركنان تأثير كذار باشد.

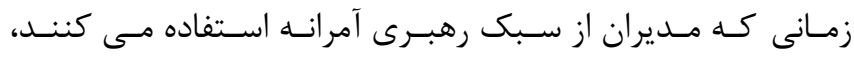

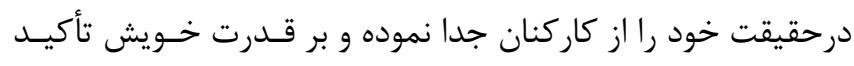

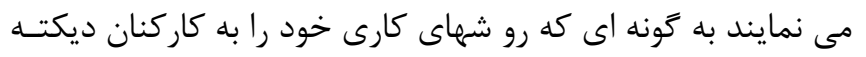

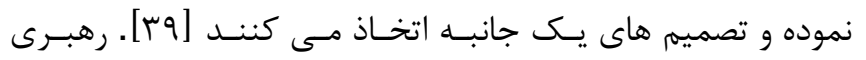

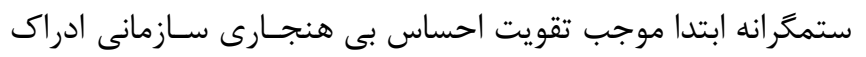

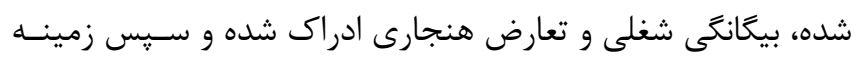

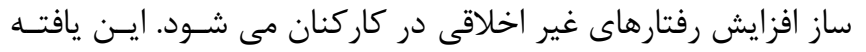

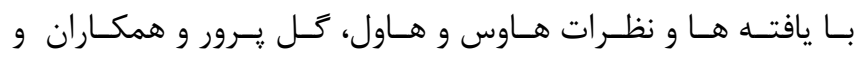

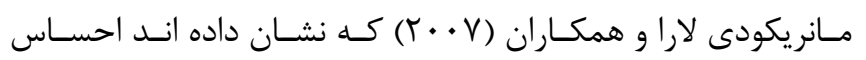

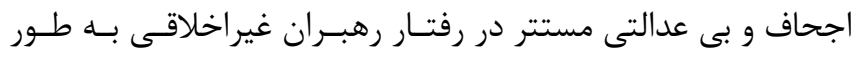
جدى مى تواند باعث احساس بى نظمى هنجارى و تعارض هنجارى

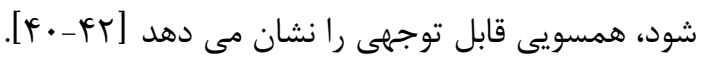

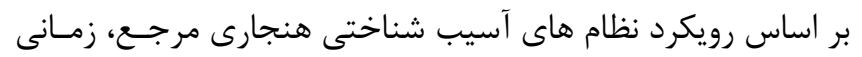

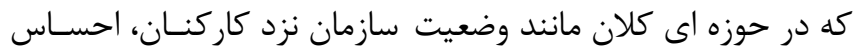

\section{بحث و نتيجه گيرى}

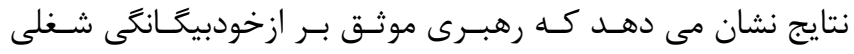

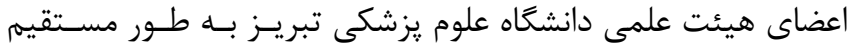

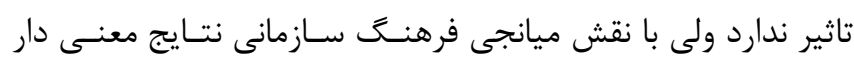
بود. از آنجا كه بيخانكى شغلى از بيامدهاى شرايط ساختارى سازمان

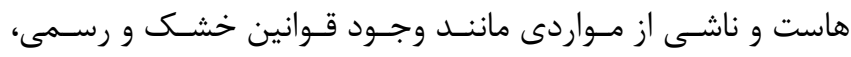
تصميم كيرى هاى متمركز و سياست هاو و رويه هاى انعطاف نايـذير

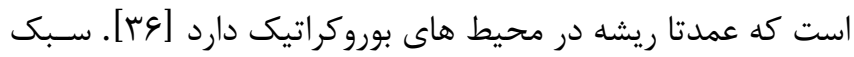

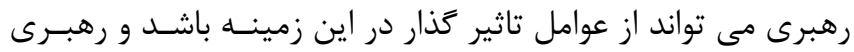
موثر با تغيير يا تعديل محيط سازمانى و روابط حاكم مى تواند اند تاند تاثير

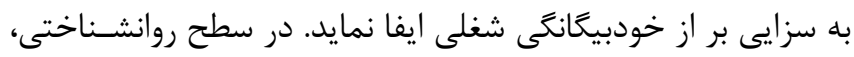

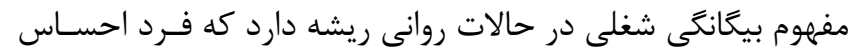

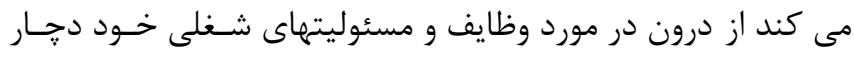

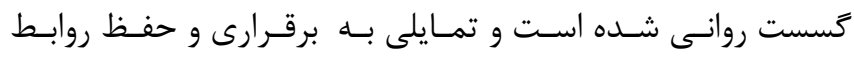

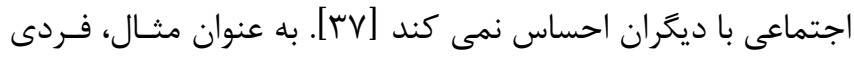

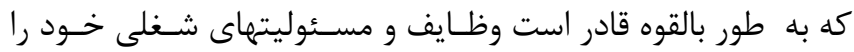

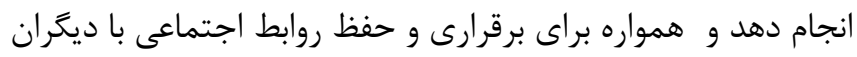

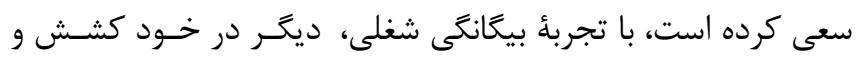




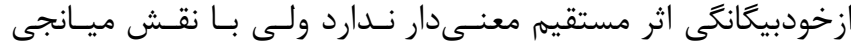

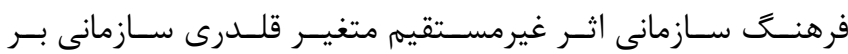

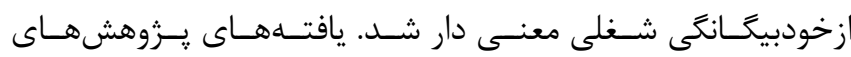

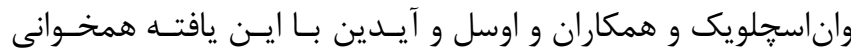

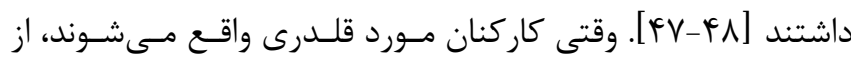

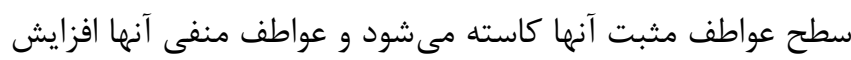

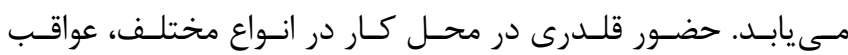

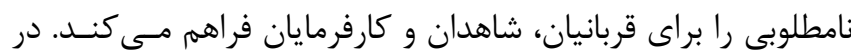

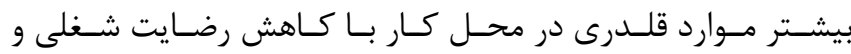

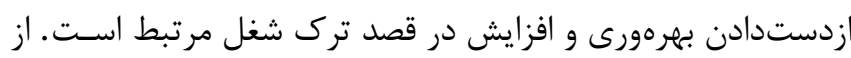
نتايج يزوهش شفيع زاده و همكاران استنباط مى شود كـه فرهنــ إنى سازمانى بر قلدرى موثر بوده و در سازمان هاى آموزشى كه اهميـت فئست

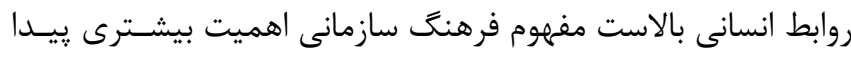

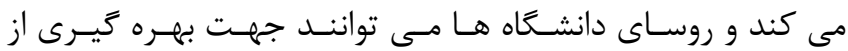

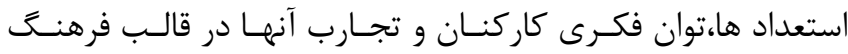

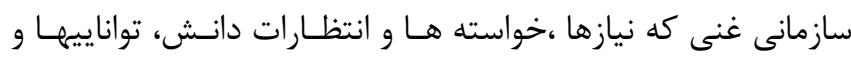

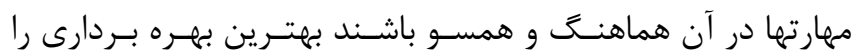

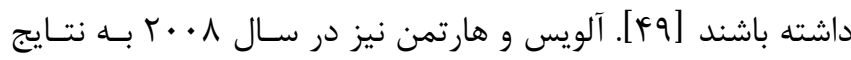
مشابه دست يافته اند [• [ه].

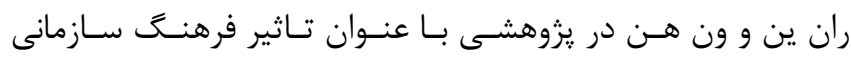

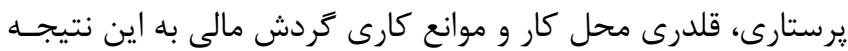

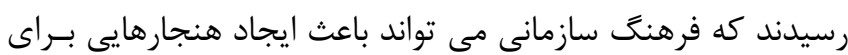

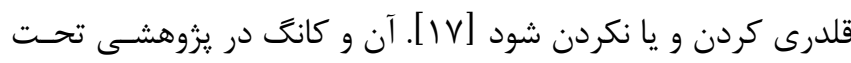

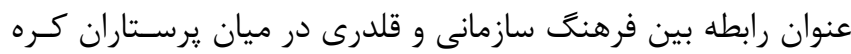

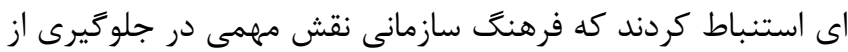

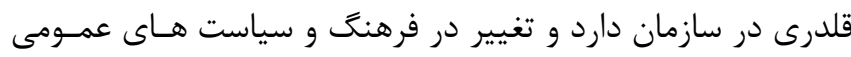

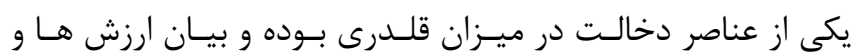
فرهنَ يك سازمان به صورت رسا و شفاف مانع از رفتارهاى قلدرانه

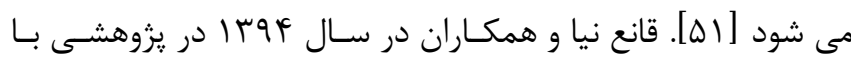

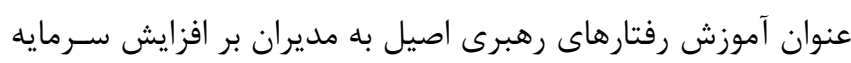

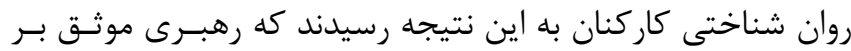

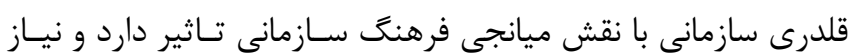

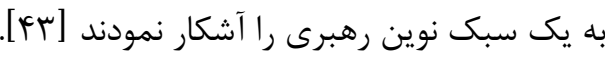

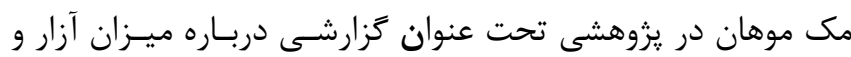

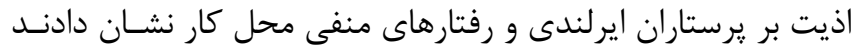

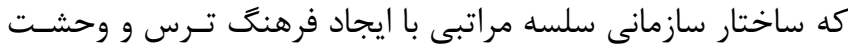

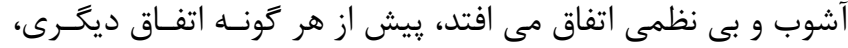

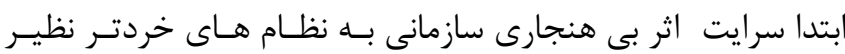

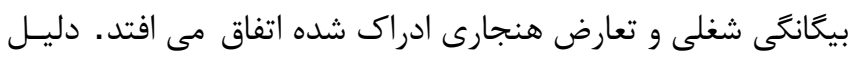

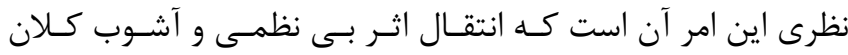

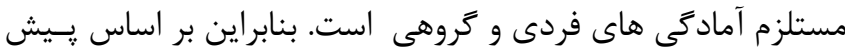

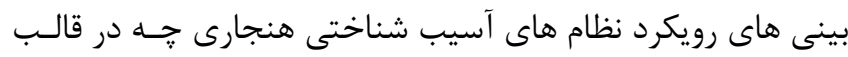

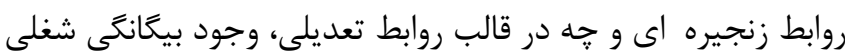

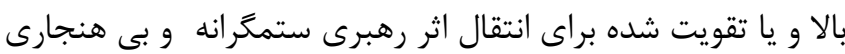

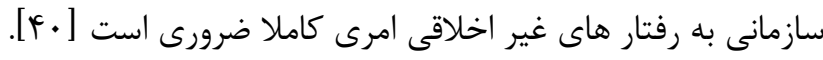

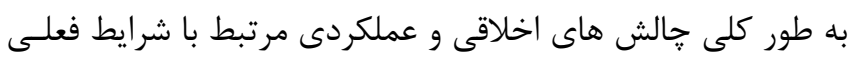

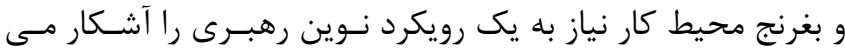

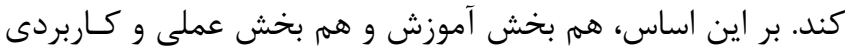

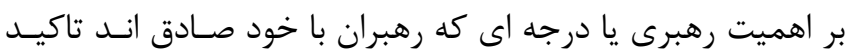

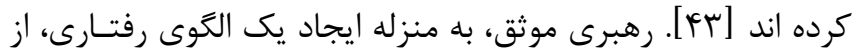

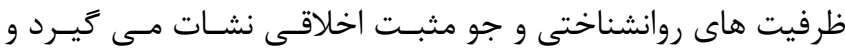

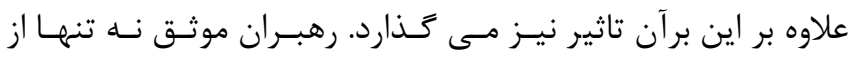

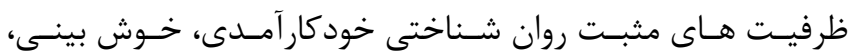
اميدوارى و تاب آورى برخوردارند، بلكه مى توانند اين كونه ظرفيت

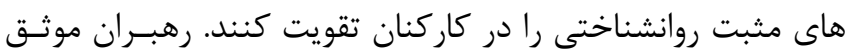

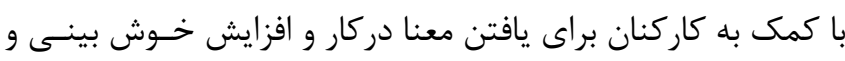

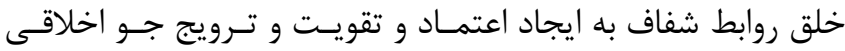

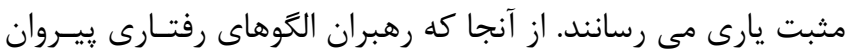

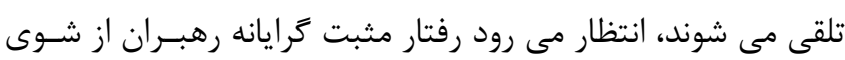

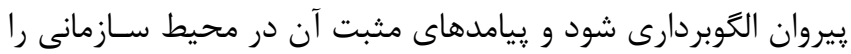

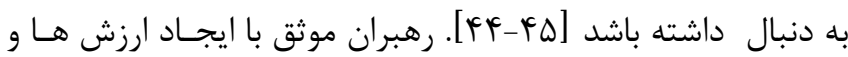

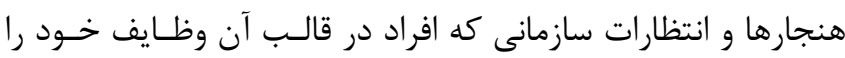

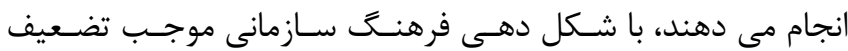

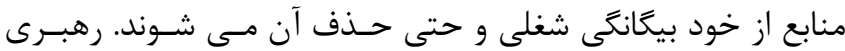

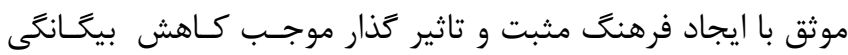

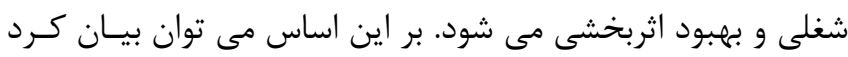
كه هرجند رهبرى موثق مى تواند اثرات مثبت و كاهنده بر اين كونه

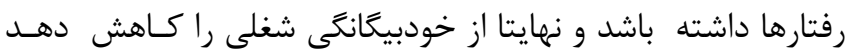

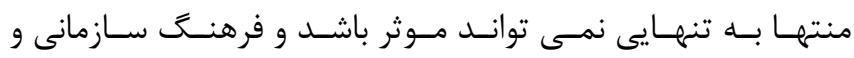

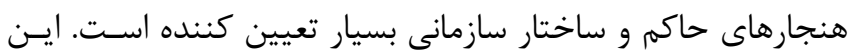

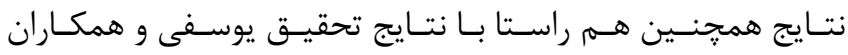

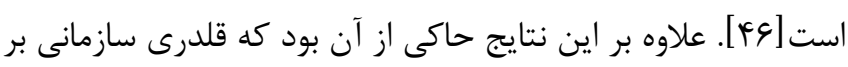




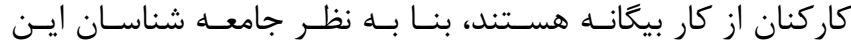

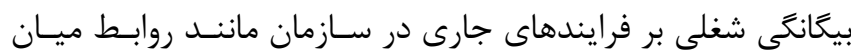

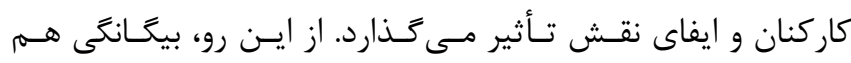

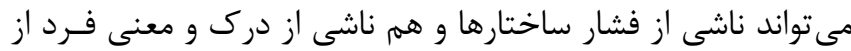

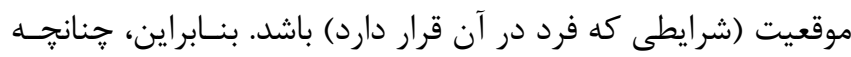

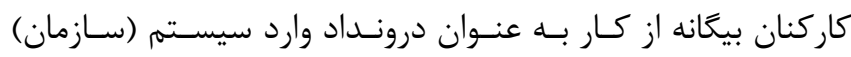

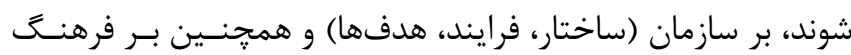

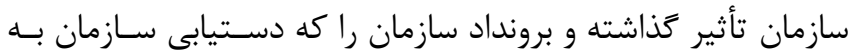

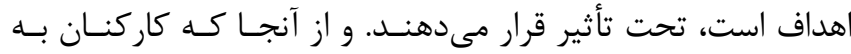

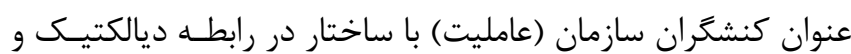
متعامل هستند، كنشكران (كاركنان) توانايى عقلانيت و دركى دائمى ساني

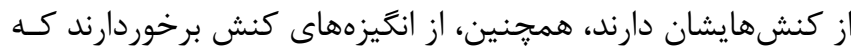

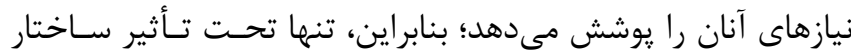

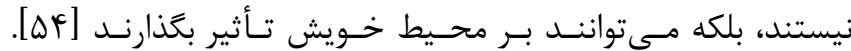

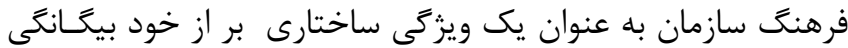

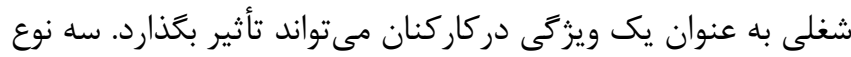

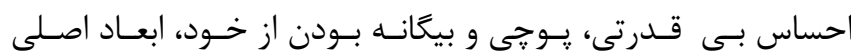

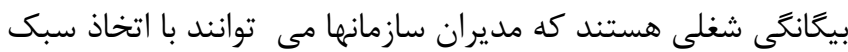

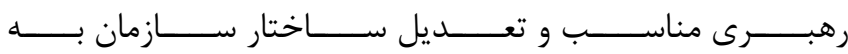
همراه فرهنخ سازمانى اثربخش، سطح بيخانكى شغلى كار كنان خود

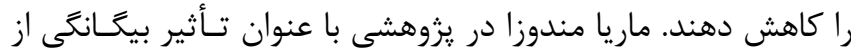

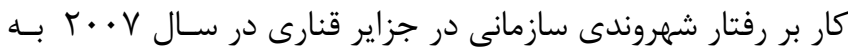

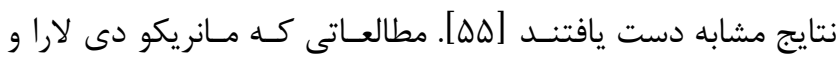

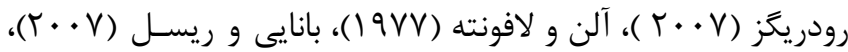

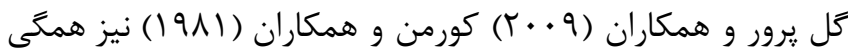

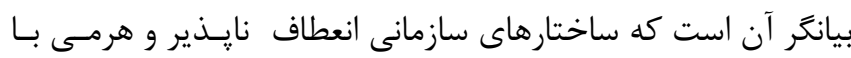

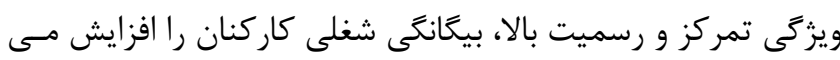

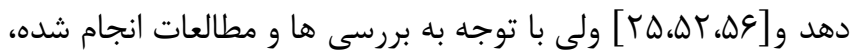

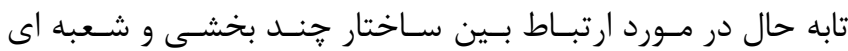

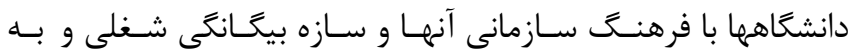
خصوص نقشى كه سبك رهبرى موثق در اين ميان مى توانــ ايفـاء نمايد، يزوهشى انجام نكرفته است.

\section{سمه نويسند كان}

فاطمه حضر تيان: مجرى اصلى طرح، ارائه طرح، تهيه مقاله بهناز مهاجران: استاد راهنماى اول طرح، كمك در نكارش حسن قلاوندى: استاد راهنماى دوم، همكارى در تجزيه و تحليل آمارى
در سازمان بين كاركنان جدايى ايجاد نموده و زمينه ساز رفتارهاى

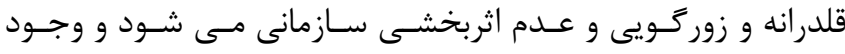

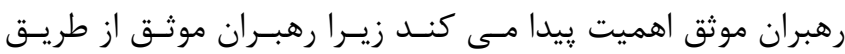

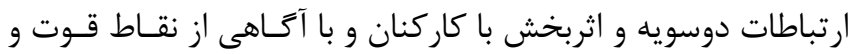

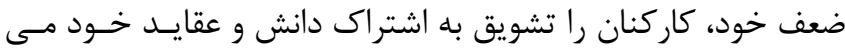

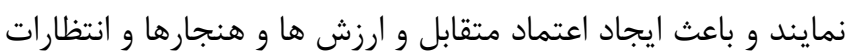

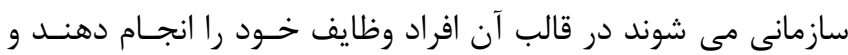

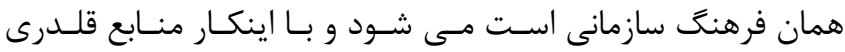

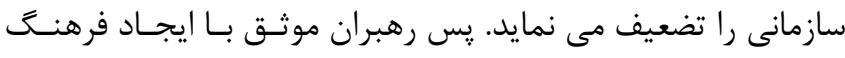

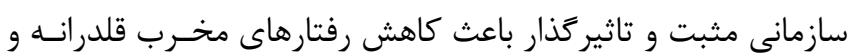
كاهش هزينه و بهبود اثربخشى سازمانى مى شوند، بنابراين رهبـرى موثق با نقش ميانجى فرهنَ سازمانى بر قلدرى سازمانى تاثير دارئ دارد

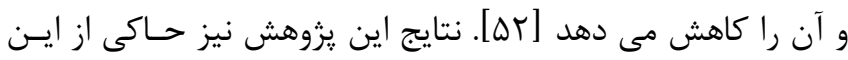

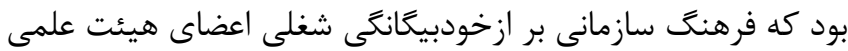

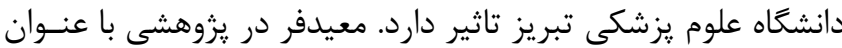

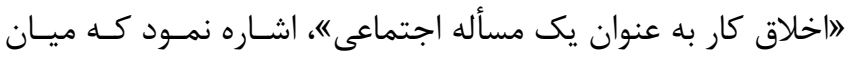

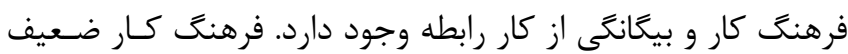

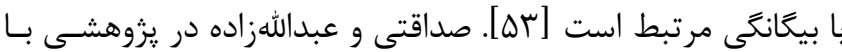
عنوان لبررسى بيكانكى شغلى و عوامل مؤثر بر آن با هدف شناسايى

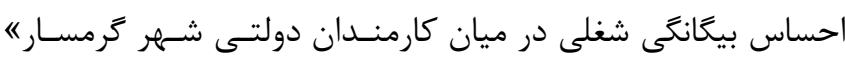

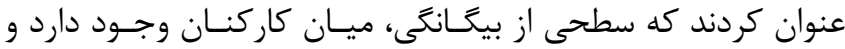

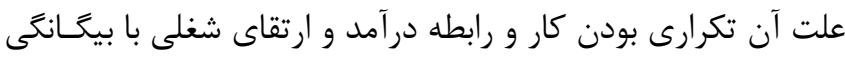

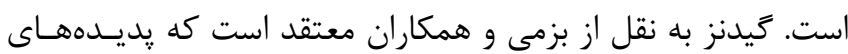

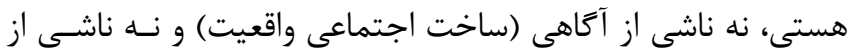

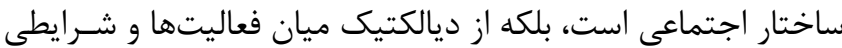

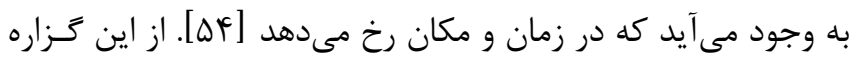

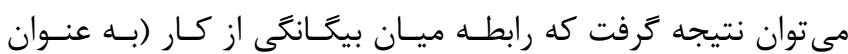

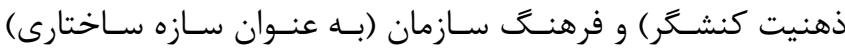

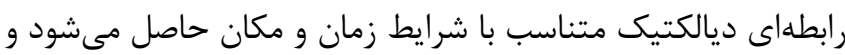

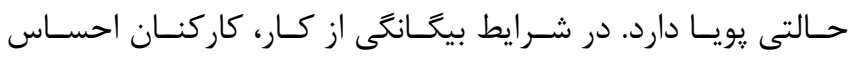
مى كنند كه در كارشان از اختيـار لازم برخـوردار نيسـتند، كارشـان إنـان يوج و بـىمعناسـت و نقشـى در موفقيـت سـازمان نــارد، كارشـان

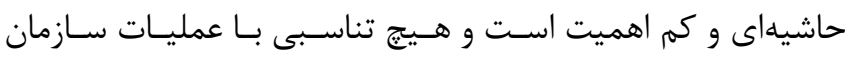

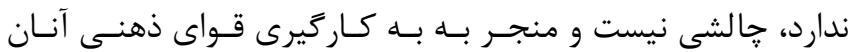
نمى شود؛ بنابراين فرصتى براى رشـــ و تعـالى در سـازمان ندارنسـد و

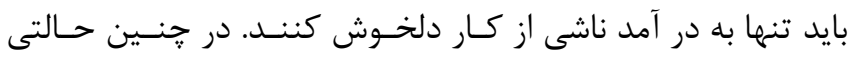




\section{منابع}

1. Abolfazli E, Saidabadi RY, Fallah VJIES. Presenting of Indifference Management Model of Education System in Ardabil Province Using Structural Equation Modeling. International Education Studies 2016; 9: 90-103 [In Persian]

2. Zameer H, Ali S, Nisar W, Amir M. The impact of the motivation on the employee's performance in beverage industry of Pakistan. International journal of Academic Research in Accounting, Finance and Management Sciences 2014 Jan;4:293-8

3. Huang J-H, Yang C, Jin B-H, Chiu HJCihb. Measuring satisfaction with business-to-employee systems. Computers in Human Behavior 2004; 20: 17-35 4. Moqadas Jafari MH, Karimi RJSSoY. A Sociological Study on the Social Participation among the Youth aged 18-29 in Bam after the Earthquake and Involving the Effective Factors. Sociological Studies of Youth Journal 2013; 4: 111-32 [In Persian]

5. Pandey SK, Welch EWJA, Society. Beyond stereotypes: A multistage model of managerial perceptions of red tape. Administration \& Society 2005; 37: 542-75

6. Banai M, Reisel WD, Probst TMJJoIM. A managerial and personal control model: Predictions of work alienation and organizational commitment in Hungary. Journal of International Management 2004; 10: 375-92

7. Einarsen S, Hoel H, Zapf D, Cooper C. Bullying and harassment in the workplace: Developments in theory, research, and practice. $2^{\text {st }}$ Edition, CRC press, London 2010

8. Keashly L, Neuman JHJAT, Praxis. Faculty experiences with bullying in higher education: Causes, consequences, and management. Administrative Theory \& Praxis 2010; 32: 48-70

9. Wong C, Cummings GJJoHO, Management. Authentic leadership: a new theory for nursing or back to basics? Journal Health Organ Mangazine 2009; 31: $1-26$

10. Lewis SE, Orford JJJoc, psychology as. Women's experiences of workplace bullying: Changes in social relationships. Journal of Community \& Applied Social Psychology 2005; 15: 29-47.

11. Laschinger HKS, Grau AL, Finegan J, Wilk PJJoan. New graduate nurses' experiences of bullying and burnout in hospital settings. Journal of Advanced Nursing 2010; 66: 2732-42
12. Avolio BJ, Gardner WL, Walumbwa FO, Luthans F, May DRJTlq. Unlocking the mask: A look at the process by which authentic leader's impact follower attitudes and behaviors. American Psychological Association 2004; 15: 801-23

13. Schein EH. Organizational culture and leadership. $4^{\text {st }}$ Edition, John Wiley \& Sons, United states of America 2010

14. Barbosa I, Cabral- Cardoso CJWiMR. Managing diversity in academic organizations: A challenge to organizational culture. Women in Management Review 2007; 4: 13-43

15. Henri J-FJA. Organizational culture and performance measurement systems. Organizations, Society $2006 ; 31: 77-103$

16. Taormina RJ. Interrelating leadership behaviors, organizational socialization, and organizational culture. Leadership \& Organization Development Journal 2008; 21: 14-33

17. Yeun Y-R, Han J-WJIJoB-S. Effect of nurses' organizational culture, workplace bullying and work burnout on turnover intention. Bio-Technology 2016; 8: $372-80$

18. Reasbeck PGJIJoCL. Relationships between doctors and managers in an acute NHS trust. Reasbeck PG. Relationships between doctors and managers in an acute NHS trust. International Journal of Clinical Leadership 2008; 16: 79-88

19. McSherry R, Pearce P. Clinical governance: a guide to implementation for healthcare professionals: $1^{\text {st }}$ Edition, John Wiley \& Sons: United states of America, 2011

20. Mostafavi rad F, Behrangi M, Asgarian M, Farzad V. The study of relationship between organizational culture, quality of work life, organizational commitment and work alienation in educational administrators of secondary schools in Shiraz. Journal of Educational Scinces 2010; 17: 4578 [In Persian]

21. Seeman MJAsr. On the meaning of alienation. American Sociological Review 1959: 783-91

22. Nadi M, Mashayekhi Z. An Analysis of the Relationship Between Organizational Socialization, Leadership Behavior, Organizational Identification and Organizational Culture with Organizational Citizenship Behavior (the Case of staff personnel of Iran's Education Ministry, Isfahan Branch). Journal of Applied Sociology 2017; 28: 153-176. Doi: 10.22108/jas.2017.21716 [In Persian] 
23. Seeman MJMop. Alienation and anomie. Measures of Personality and social Psychological Attitudes 1991; 1: 291-371

24. Hirschfeld RR, Feild HSJJoOBTIJoI, Occupational, Psychology O, Behavior. Work centrality and work alienation: Distinct aspects of a general commitment to work. The International Journal of Industrial, Occupational and Organizational Psychology and Behavior 2000; 21: 789-800

25. Gholipour A, Bod M, Fakheri KS, Baghestani BH. Perceived Organizational Bullying Relationship with Women's Stress. Social Welfare 2009; 9: 187-205 [In Persian]

26. Razi Moradi M, Etemadi A, Naeimabbadi EJJoPS. The effectiveness of group counseling based on william glasser's choice theory with bully victimizing students to increase ability to encounter with bullying behaviors. Clinical Psychology Studies 2010; 6: 11-28 [In Persian]

27. Nikpay I, Zand Karimi MJOCM. The Impact of Authentic Leadership on Organizational Bullying with the Mediating Role of Organizational Culture. Organizational Culture Management 2019; 17: 317-36 [In Persian]

28. Djurkovic N, McCormack D, Casimir GJHRMJ. Workplace bullying and intention to leave: the moderating effect of perceived organizational support. Human Resource Management Journal 2008 18: 405-22.

29. Agervold MJSjop. The significance of organizational factors for the incidence of bullying. Scandinavian Journal of Psychology 2009; 50: 267-76

30. Roof RJAJoBE. Authentic leadership questionnaire (ALQ) psychometrics. Asian Journal of Business Ethics 2014; 3: 57-64

31. Denison DR, Janovics J, Young J, Cho HJJDdtDCG. Diagnosing organizational cultures: Validating a model and method. Denison Consulting Group 2006; 17: 1-39

32. Nikpay I, Zand Karimi M. The Impact of Authentic Leadership on Organizational Bullying with the Mediating Role of Organizational Culture. J Organizational Culture Management 2019; 17: 317-36

33. Fornell C, Larcker DFJJomr. Evaluating structural equation models with unobservable variables and measurement error. Journal of Marketing Research 1981; 18: 39-50

34. Chin WW. Commentary: Issues and opinion on structural equation modeling. MIS Quarterly 1998; 22: $7-17$
35. Henseler J, Ringle CM, Sinkovics RR. The use of partial least squares path modeling in international marketing. New challenges to international marketing: Emerald Group Publishing Limited 2009; 20: 277-319.

36. Foster MK, Angus BB, Rahinel RJL, Journal OD. "All in the hall" or "sage on the stage". Leadership \& Organization Development Journal 2008; 29: 504-521

37. Sulu S, Ceylan A, Kaynak RJJJoB, Management. Work alienation as a mediator of the relationship between organizational injustice and organizational commitment: Implications for healthcare professionals. International Journal of Business and Management 2010; 5: 27

38. Giritli Nygren $\mathrm{K}$, Lindblad-Gidlund KJtJfaGSISUToIRG. The pastoral power of technology. Rethinking alienation in digital culture. Marx in the Age of Digital Capitalism 2012; 10: 509-17 39. Pelletier KLJL. Leader toxicity: An empirical investigation of toxic behavior and rhetoric. Leadership 2010; 6: 373-89

40. Golparvar M, Nadi MAJJOSS. Investigating the Role of Organizational Anomie in Moderating the Relationship between University Faculty Members' Attitudes with Organizational Citizenship Behaviors. Journal of Social Sciences 2010: 0-141

41. House RJ, Howell JMJTLQ. Personality and charismatic leadership. The Leadership Quarterly. 1992; 3: 81-108

42. Baharom MN, Sharfuddin MD, Iqbal J. A systematic review on the deviant workplace behavior. Review of Public Administration and Management 2017; 5:1-8

43. Ghane Niya $M$, Arshadi N, Bashlide $K$, Farvahar MJjjoms. The effectiveness of authentic leadership training of managers on employee's psychological capital: An experimental study in a Petrochemical Company. Iranian journal of Management Ssciences 2015; 10: 98-123

44. Poormokhtari E, karimi f. The relationship between perceptions of authentic leadership and staff's deviant behaviors in education organization of Isfahan City. The Journal of Modern Thoughts in Education 2017; 12: 55-68

45. Norman SM, Avolio BJ, Luthans FJTLQ. The impact of positivity and transparency on trust in leaders and their perceived effectiveness. The Leadership Quarterly 2010; 21: 350-64 
46. Yousefi B, Eydipour K, gholami torkesaluye s. Relationship between authentic leadership style with job interest of General Sport and Young offices employments of west provinces of Iran. Scientific Journal of Organizational Behavior Management in Sport Studies 2016; 2: 57-63 [In Persian]

47. Van Schalkwyk L-M, Els C, Rothmann Jr IJSJoHRM. The moderating role of perceived organisational support in the relationship between workplace bullying and turnover intention across sectors in South Africa. Journal of Human Resource Management 2011; 9: 1-13

48. Öcel HJIJoB, Science S. Workplace bullying and turnover intention: The moderating role of belief in a just world. International Journal of Business and Social Science 2012; 3: 248-258

49. shafeipourmotlagh f, Molla Ahmadi M. The Relationship between Using Self-Regulatory Skills and Educational Self-Esteem by Developing Perceived Mastermind's Curriculum in the Entrepreneur's School. Journal Educational Researches 2020; 15: 63-84

50. Seidler de Alwis R, Hartmann EJJokM. The use of tacit knowledge within innovative companies: knowledge management in innovative enterprises. Journal of knowledge Management 2008; 12: 133-147. 51. An Y, Kang JJAnr. Relationship between organizational culture and workplace bullying among Korean nurses. Asian Nursing Research 2016; 10: 234-9

52. McMahon J, MacCurtain S, O'Sullivan M, Murphy C, Turner TJDIN, Organization M. A report on the extent of bullying and negative workplace behaviors affecting Irish nurses. Dublin Irish Nurses and Midwives Organization 2013; 1: 1-44
53. Moeidfar S. Work Ethics among State Office Employees of the Tehran Provincial Administration. Journal Social Welfare 2007; 6: 321-44

54. Bazmi $M$, Haghighatian $M$, Ansari ME, Vahida FJJoAS. Sociological Assessment of Job Alienation and its Impacts on Organizational Culture in Educational Organizations (the Case of Educational Staff in Mashhad). Journal of Applied Sociology 2014; 25: 1-14 [In Persian]

55. Suárez Mendoza MJ, Zoghbi Manrique deLara PJIjooA. The impact of work alienation on organizational citizenship behavior in the Canary Islands. International Journal Of Organizational Analysis 2007; 15: 56-76

56. Lara PZMd, Rodriguez TFEJPR. Organizational anomie as moderator of the relationship between an unfavorable attitudinal environment and citizenship behavior (OCB): An empirical study among university administration and services personnel. Personnel Review 2007; 36: 843-66

57. Allen BH, LaFollette WRJAoMJ. Perceived organizational structure and alienation among management trainees. Academy of Management Journal 1977; 20: 334-41

58. Banai M, Reisel WDJJoWB. The influence of supportive leadership and job characteristics on work alienation: A six-country investigation. Journal of World Business 2007; 42: 463-76

59. Korman AK, Wittig-Berman U, Lang DJAomj. Career success and personal failure: Alienation in professionals and managers. Academy of Management Journal 1981; 24: 342-60 